ARTICLE

\title{
The HSP90/R2TP assembly chaperone promotes cell proliferation in the intestinal epithelium
}

\author{
Chloé Maurizy (10 1,2, Claire Abeza (1) 1,2,9, Bénédicte Lemmers (10 1,9, Monica Gabola1, Ciro Longobardi (1) 1, \\ Valérie Pinet ${ }^{1}$, Marina Ferrand ${ }^{1}$, Conception Paull', Julie Bremond1', Francina Langa (1) ${ }^{3}$, François Gerbe ${ }^{2,4}$, \\ Philippe Jay (D) 2,4, Céline Verheggen (1D ${ }^{1,2,8}$, Nicola Tinari ${ }^{5}$, Dominique Helmlinger (iD ${ }^{6}$, Rossano Lattanzio (i) ${ }^{7}$,

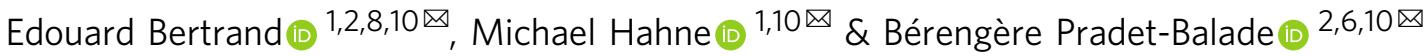

The R2TP chaperone cooperates with HSP9O to integrate newly synthesized proteins into multi-subunit complexes, yet its role in tissue homeostasis is unknown. Here, we generated conditional, inducible knock-out mice for Rpap3 to inactivate this core component of R2TP in the intestinal epithelium. In adult mice, Rpap3 invalidation caused destruction of the small intestinal epithelium and death within 10 days. Levels of R2TP substrates decreased, with strong effects on mTOR, ATM and ATR. Proliferative stem cells and progenitors deficient for Rpap3 failed to import RNA polymerase II into the nucleus and they induced p53, cell cycle arrest and apoptosis. Post-mitotic, differentiated cells did not display these alterations, suggesting that R2TP clients are preferentially built in actively proliferating cells. In addition, high RPAP3 levels in colorectal tumors from patients correlate with bad prognosis. Here, we show that, in the intestine, the R2TP chaperone plays essential roles in normal and tumoral proliferation.

\footnotetext{
${ }^{1}$ IGMM, Univ Montpellier, CNRS, Montpellier, France. ${ }^{2}$ Equipe labélisée Ligue Nationale Contre le Cancer, Paris, France. ${ }^{3}$ Centre d'Ingénierie Génétique Murine, Institut Pasteur, Paris, France. ${ }^{4}$ IGF, Univ Montpellier, CNRS, INSERM, Montpellier, France. ${ }^{5}$ Department of Medical, Oral and Biotechnological Sciences, Center for Advanced Studies and Technology (CAST), 'G. d'Annunzio' University of Chieti-Pescara, Chieti, Italy. ${ }^{6}$ CRBM, Univ Montpellier, CNRS, Montpellier, France. ${ }^{7}$ Department of Innovative Technologies in Medicine \& Dentistry, Center for Advanced Studies and Technology (CAST), 'G. d'Annunzio' University of Chieti-Pescara, Chieti, Italy. ${ }^{8}$ IGH, Univ Montpellier, CNRS, Montpellier, France. ${ }^{9}$ These authors contributed equally: Claire Abeza, Bénédicte Lemmers. ${ }^{10}$ These authors jointly supervised this work: Edouard Bertrand, Michael Hahne, Bérengère Pradet-Balade. ${ }^{凶}$ email: edouard.bertrand@igh.cnrs.fr; hahne@igmm.cnrs.fr; pradet@crbm.cnrs.fr
} 
T he R2TP complex was first discovered in Saccharomyces cerevisiae as an HSP90 co-chaperone ${ }^{1}$. HSP90 folds hundreds of substrate proteins (also called "clients") into their native, active state ${ }^{2}$. The chaperone activity of HSP90 is coupled with its ATPase cycle and is regulated by a number of co-factors called co-chaperones. These co-chaperones aid client loading and regulate the HSP90 ATPase cycle ${ }^{2}$. R2TP is an HSP90 cochaperone but is unusual for two reasons: first, it is composed of four different subunits; second, it is specialized in quaternary protein folding, i.e., it enables the incorporation of clients into multi-subunit complexes (for review ${ }^{3}$ ). In mammals, R2TP is composed of a heterodimer between PIH1D1 and RPAP3, which associates with a heterohexamer of RUVBL1 and RUVBL2 (Fig. 1a). PIH1D1 and RPAP3 are both involved in substrate recognition ${ }^{4,5}$ while RPAP3 also recruits the chaperones HSP90 and HSP706,7. RUVBL1 and RUVBL2 are related AAA+ ATPases that also have chaperone activity ${ }^{8,9}$. Multiple contacts between the PIH1D1:RPAP3 heterodimer and the RUVBL1/2 heterohexamer allow regulation of their ATPase activity ${ }^{7,10-12}$. Importantly, the RPAP3:PIH1D1 heterodimer is specific to R2TP whereas RUVBL1/2 are also part of other complexes such as the chromatin remodelers INO80 and SRCAP ${ }^{13}$. In mammals, R2TP also associates with a set of six prefoldins and prefoldin-like proteins, possibly to help protein folding. Altogether, R2TP associated with prefoldins has been termed the PAQosome, for Particle for Arrangement of Quaternary structure ${ }^{3}$.

The first documented R2TP clients were the small nucleolar ribonucleoparticles (snoRNPs), which are required for the maturation of ribosomal RNAs ${ }^{14,15}$. These particles can be grouped into two families, the C/D and H/ACA snoRNPs, each family being characterized by a set of four proteins, which assembles with a variety of small nucleolar RNAs. Later on, other R2TP substrates have been identified, including the U4 and U5 spliceosomal snRNPs ${ }^{16-18}$, the nuclear RNA polymerases ${ }^{19,20}$, MRE11 ${ }^{21}$, and the PI3K-like kinases (PIKKs) mTOR, ATR, ATM, DNA-PK, and SMG-122. R2TP clients thus include several multimeric cellular complexes with crucial roles in transcription, ribosome biogenesis, DNA repair and cell growth ${ }^{3,23}$, yet the role of R2TP in tissue homeostasis has not been studied. Most of our knowledge about R2TP originates from work in S.cerevisiae, mammalian cell lines or in vitro studies with recombinant proteins. In S.cerevisiae, R2TP is mostly required under stress conditions ${ }^{14,24,25}$. In D. melanogaster, knockdown of Spag, RPAP3 ortholog, compromises early development and germline stem cells, but not somatic organogenesis nor homeostasis ${ }^{26,27}$. The role of HSP90 on tissue development is also poorly documented. Constitutive knockout $(\mathrm{KO})$ murine models showed that one cytosolic paralog of HSP90 was necessary for spermatogenesis while the other one was essential for early development ${ }^{28,29}$. Conditional models to characterize the role of HSP90 and R2TP in specific tissues are still missing.

In this study, we chose to address the role of R2TP in the intestine, the most dynamically self-renewing tissue in adult mammals. The intestine has a well-defined architecture, which is particularly amenable to study cell proliferation and differentiation ${ }^{30}$. Briefly, active stem cells called Crypt Base Columnar (CBC) stem cells reside at the bottom of intestinal crypts, where they divide to either self-renew, or give rise to progenitors (see below). Progenitors migrate through the transient amplifying (TA) compartment to undergo several division rounds and then differentiate. Differentiated cells migrate towards the villus tip, where they ultimately undergo apoptosis and are shed off the tissue ${ }^{31}$. Progenitors can differentiate into enterocytes, responsible for water and nutrient absorption and compose most of the small intestine epithelium. Alternatively, progenitors differentiate into one of the secretory subtypes.
Among these, the goblet cells are the most represented. These cells produce a lubricant protective mucus layer, and their density increases from the duodenum to the colon. In the small intestine, CBC stem cells also generate long-lived Paneth cells (3-6 weeks), which secrete anti-microbial peptides and maintain crypt niche conditions (for review ${ }^{31}$ ).

In this work, we generated murine models bearing a conditional KO allele of Rpap3 to study the role of R2TP in intestinal homeostasis. Indeed, RPAP3 is central to R2TP, bridging together HSP90, HSP70, PIH1D1, and RUVBL1/27,10-12. Our work uncovered a crucial role of R2TP in CBC stem cells and progenitors, where it couples the assembly of key cellular machineries with proliferation. In agreement with a link between R2TP and cell proliferation, we found that high RPAP3 expression in human colorectal cancer (CRC) tissues is associated with shorter disease-free survival (DFS) in patients.

\section{Results}

Rpap3 is an essential gene in mice. To generate Rpap3 murine models, we tested different recombinant murine Embryonic Stem cells (ES cells) available from the KOMP consortium (Supplementary Fig. 1a, b). In the Rpap $3^{\text {wtsi }}$ allele, a strong acceptor splice site is introduced before exon 7. The resulting mRNA encodes a Rpap $3^{\text {wtsi }}$ protein truncated after the first TPR domain, at amino acid 223, followed by a selection cassette and the bacterial $\beta$-galactosidase gene (Supplementary Fig. 1a, b). Sitespecific recombination at the Rpap3 locus was confirmed by Southern blot in the H10 clone (Supplementary Fig. 1c). Injection of H10 ES cells into blastocysts generated 3 chimeras with germinal transmission. Intercrossing of Rpap $3^{w t s i /+}$ animals did not yield any homozygous Rpap $3^{\text {wtsi/wtsi }}$ animal, suggesting that this truncated Rpap3 allele is homozygous lethal (0/34 pups; Supplementary Fig. 1a, b).

We used the $\beta$-galactosidase cassette to characterize Rpap3 expression. In the small intestine of Rpap $3^{\text {ttsi } /+}$ animals, we detected $\beta$-galactosidase activity exclusively at the bottom of the crypts, intercalated between lacZ negative cells (Fig. 1b). This could correspond to either CBC stem cells or Paneth cells (see below for a schematic representation of the small intestinal crypts). Pihld1 interacts with Rpap3, and this interaction is crucial for Pih1d1 stability and R2TP activity ${ }^{32}$. Pih1d1 is detected in $\mathrm{CBC}$ stem cells and progenitors but not in Paneth cells nor differentiated cells of the villus (Fig. 1c and below for a schematic representation of the crypts). In the colon, LacZ activity is weak, Pihld1 is undetectable and both are absent from the stroma (Fig. 1c). Overall, R2TP expression is restricted to proliferative cells.

Rpap3 is required for small intestine maintenance. To generate a conditional KO strain, Rpap $3^{\text {wtsi/+ }}$ mice were crossed with mice carrying a transgene encoding the Flipase $\mathrm{Fl}^{33}$. In the progeny, excision of the Flp-in cassette produced a Rpap3 allele with exon 7 flanked by loxP sites (Supplementary Fig. 1a). Rpap $3^{f l o x}$ mRNA encodes a protein identical to wild-type Rpap3. Indeed, there was no bias in transmission nor any obvious phenotype in Rpap3flox/ flox mice. Excision of exon 7 by Cre-recombinase produces a $R$ pap $3^{\Delta 7}$ mRNA with a premature termination codon in exon 8 , predicted to be degraded by the nonsense-mediated decay pathway (Supplementary Fig. 1a, b).

To obtain a constitutive deletion of Rpap3 in the intestinal epithelium, Rpap3flox/flox mice were crossed with villin-Cre ( VilCre) transgenic mice. The VilCre transgene encodes a constitutively active Cre that is specifically expressed in the epithelial cells of the small and large intestine ${ }^{34}$. We were unable to generate homozygous VilCre; Rpap $3^{\text {flox/flox }}$ animals $(0 / 100$ 
a

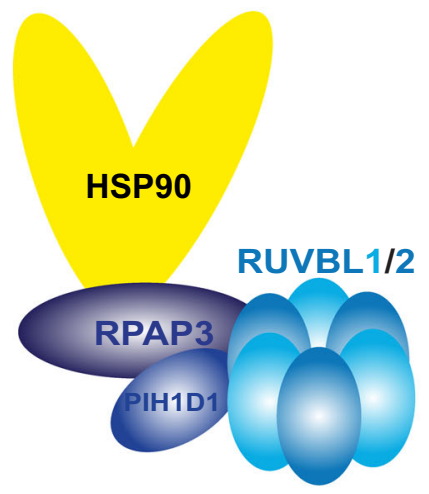

R2TP b lacZ activity in Rpap3 ${ }^{\text {wtsil+ }}$ small intestine
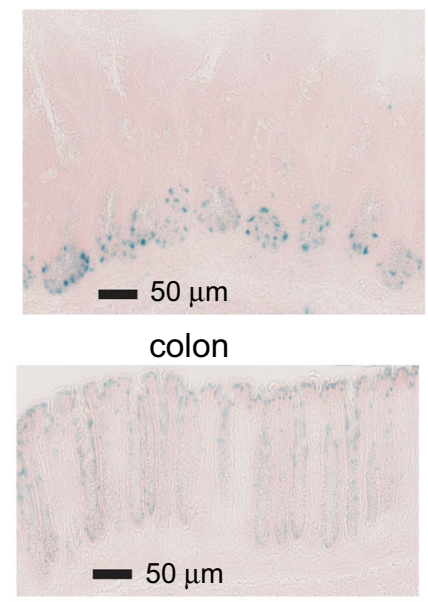

NC

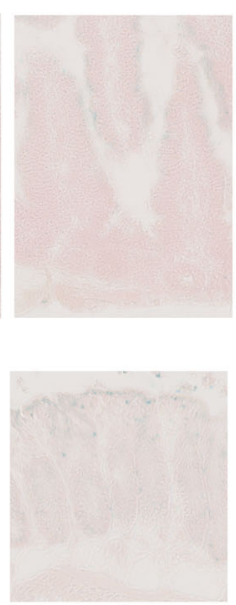

Pih1d1 small intestine

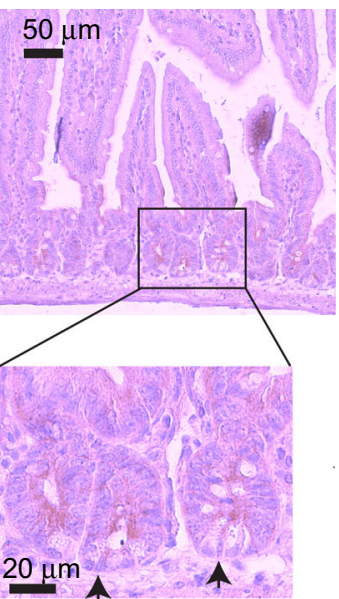

d WB at day 5: small intestine (jejunum)

colon

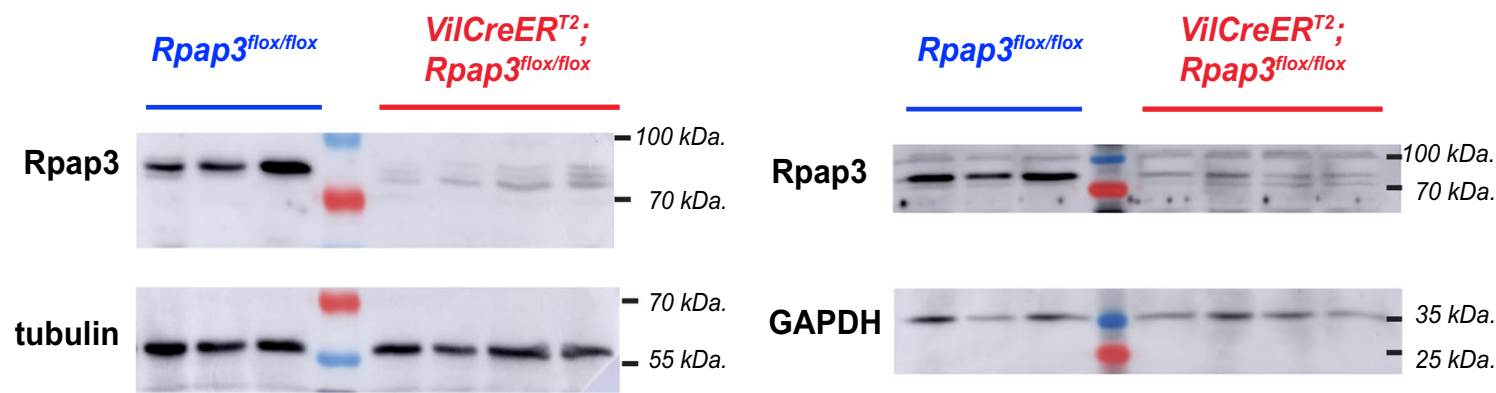

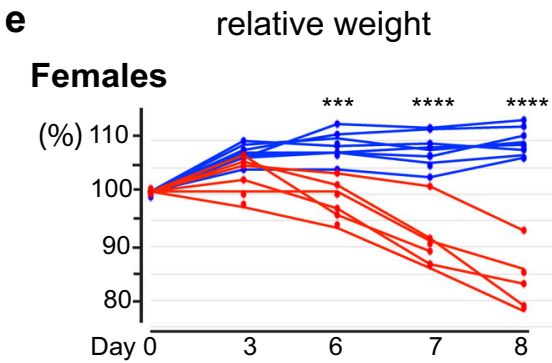

\section{Males}

(\%)

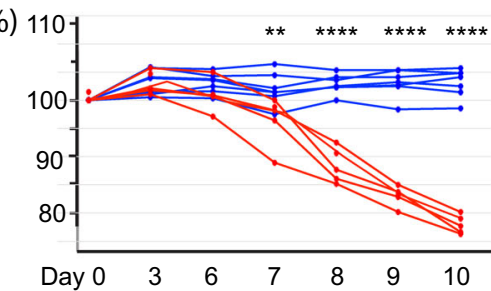

f organ length
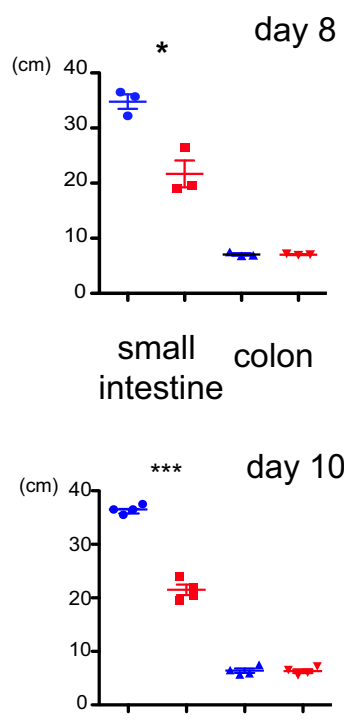

g day $8-10$

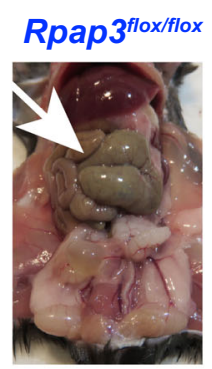

VilCreER $R^{T 2 ;}$ Rpap3 flox/flox
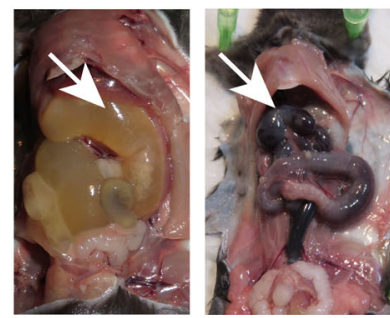

pups; Supplementary Fig. 1a), showing that the absence of Rpap3 in the intestinal epithelium is lethal. To bypass this problem, we turned to an inducible CreER ${ }^{\mathrm{T} 2}$ under the control of the same promotor (VilCreER ${ }^{T 2}$ ). This Cre-recombinase is also specifically expressed in the intestinal epithelium but needs to be activated by tamoxifen ${ }^{34}$. VilCreER $R^{T 2}$; Rpap $3^{\text {flox/flox }}$ animals were healthy and did not present any obvious phenotype. We then injected intraperitoneally two doses of tamoxifen separated by an interval of $24 \mathrm{~h}$ in 8 -week-old mice because the intestine is fully developed at this age. This yielded an efficient recombination, already detectable 1 day after the first injection and only in the small intestine and colon epithelium but not in any of the other organs tested (Supplementary Fig. 1d, e). As a consequence, Rpap3 protein was no longer detected in epithelia from jejunum and 
Fig. 1 Rpap3 deletion compromises the small intestine and mouse survival. a Schematic representation of R2TP with its four subunits (RPAP3, PIH1D1, and the RUVBL1/2 heterohexamer). RPAP3 is the core subunit that contacts directly HSP90, PIH1D1 and RUVBL1/2. b $\beta$ galactosidase activity in Rpap3wtsi/+ small intestines (top) and colon (bottom), as compared to negative controls $(n=2)$. Scale bars $=50 \mu \mathrm{m}$ are identical for all images. $\mathbf{c} I H C$ of Pih1d1 in the small intestine. Counter coloration of DNA with hematoxylin, with magnification (bottom). Top picture: bar represents $50 \mu \mathrm{m}$. Inset: arrows point to CBC stem cells, intercalated between Paneth cells with distinctive granules in the cytoplasm; bar is $20 \mu \mathrm{m}$. Micrograph is representative of $n=3$. d Depletion of Rpap3 after tamoxifen injection. Western blots were revealed with antibodies against the indicated proteins in extracts of the jejunum (left) and the colonic (right) epitheliums of RPAP3flox/flox controls (blue) or VilCreER T2; RPAP3flox/flox animals (red), 5 days after the first tamoxifen injection. Each lane was loaded with the lysate obtained from a single animal and were verified for $n=12$ small intestines and 8 colons, in three independent experiments. Molecular sizes are indicated on the right. e Individual weight variations in females (top panel) and males (bottom panel) of tamoxifen treated VilCreER ${ }^{T 2}$; RPAP3flox/flox animals (red curves, $n=6$ females and $n=5$ males) and RPAP3flox/flox controls (blue curves, $n=8$ females and $n=6$ males). Individual weights were set at $100 \%$ for each animal at day 0 , and analyzed by two-way ANOVA (genotype affects weights with $p<0.0001$ in male and females) and Bonferroni's post hoc multiple comparison tests ( ${ }^{\star \star} p<0.01 ;{ }^{\star \star \star} p<0.001 ;{ }^{\star \star \star \star} p<0.0001$-see Source Data). $\mathbf{f}$ Length of small intestines and colons from VilCreER ${ }^{T 2} ; R P A P 3^{f l o x} / f l o x$ mice (red points) and controls (blue points) measured at day 8 and day 10 of females (top, $n=3$ ) and males (bottom, $n=4)$ were analyzed by two-tailed unpaired $t$ test with Welch's correction (females: ${ }^{\star} p=0.0177, t=4.750, \mathrm{df}=3$; males: ${ }^{\star \star \star} p=0.0001, t=14.14$, df $=4$ ). Statistics data represent individual assays with mean \pm S.E.M. $\mathbf{g}$ Representative images of small intestine (white arrowheads) from VilCreER ${ }^{T 2}$; RPAP3flox/flox animals, which were filled with liquid (left panel) or blood (right panel) from day 8 to 10; a control organ is shown above. Source data are provided as a "Source Data file".

strongly reduced in colon, 5 days after the first tamoxifen injection (Fig. 1d).

VilCreER ${ }^{T 2}$; Rpap $3^{\text {flox/flox }}$ mice showed no obvious phenotype during the first days following tamoxifen injection but suffered from an important weight loss from day 6 onwards, such that most females and males had to be sacrificed from day 8 to 10 (Fig. 1e). The small intestines from these animals were shorter than those of controls and displayed a massive swelling with a transparent liquid or blood (Fig. 1f, g). Histological analysis revealed no alteration in the small intestine of $V i l C r e E R^{T 2}$; $R p a p 3^{f o x} / f l o x$ mice within the first 6 days. At day 7, however, villi epithelial cells presented an altered morphology with surface enterocyte disorganization and focal crowding (Fig. 2a, b red square). At day 8 , there was a severe destruction of the small intestinal architecture with villous atrophy and tufts of extruding epithelium (Fig. 2b). In contrast, the intestines of the VilCreER ${ }^{T 2}$; Rpap3flox/t mice did not show any phenotype (Fig. 2b), suggesting that under normal conditions, one allele of wild-type Rpap3 is sufficient to maintain tissue homeostasis.

Rpap3 promotes cell proliferation within the epithelium. To understand the basis for this rapid degeneration of the intestinal epithelium, we characterized Ki67 expression. Ki67 marks proliferative cells which are, in the intestine, the CBC stem cells and progenitors from the TA compartment (Fig. 3a, b). Immunostaining revealed a loss of $\mathrm{Ki} 67$ in the crypts of $\operatorname{VilCreER}{ }^{T 2}$;

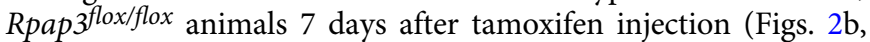
$3 c)$. To directly monitor cell cycling, BrdU was injected into the mouse peritoneum $2 \mathrm{~h}$ before sacrifice. BrdU is a nucleoside analog incorporated into the DNA during S-phase. BrdU staining was comparable from day 1 to day 6 in the crypts of control and VilCreER ${ }^{T 2}$; Rpap3 $3^{\text {flox/flox }}$ animals. At day 7 however, there were significantly less BrdU ${ }^{+}$cells (Fig. $3 \mathrm{~d}$, e). This is coherent with the loss of Ki67 staining and confirms cycle arrest in the crypts and the TA compartment of the mutant animals. At day 8, the atrophic small bowel mucosa showed remnants of crypt glands with some $\mathrm{Ki}^{+}{ }^{+}$cells (Fig. 2b, black arrowheads). Overall, such epithelium destruction, with remnants of Ki67+ crypt glands, phenocopies TCF4 loss ${ }^{35}$. TCF4 is the transcription factor that integrates Wnt signaling to sustain CBC stemness program ${ }^{36}$. This suggests that R2TP may be required for both $\mathrm{CBC}$ and progenitors.

To directly analyze CBC stem cells, we performed immunostaining for Olfm4, a trans-membrane protein commonly used for CBC identification $^{37}$ (Fig. 4a, b and Supplementary Fig. 4a). Olfm4 staining was similar between control and VilCreER ${ }^{T 2}$; Rpap $3^{\text {flox/flox }}$ mice from day 4 to day 6 after tamoxifen injection. However, at days 7 and 8, Olfm4 expression was undetectable in most VilCreER ${ }^{T 2}$; Rpap3flox/flox crypts (Fig. 4a, b and Supplementary Fig. 2a), in agreement with the loss of $\mathrm{Ki}^{+}{ }^{+}$staining (Figs. 2b, 3c). In the crypts, CBC stem cells intercalate between larger differentiated cells, called Paneth cells. These cells are $\mathrm{Ki}^{-} 7^{-}$and recognizable with the lysozyme marker (Fig. 4c, d) or by their typical supranuclear eosinophilic (cytoplasmic) granules stained by Hematoxylin/Eosin (HE; Fig. 3c). In marked contrast to CBC stem cells, Paneth cells were detected in a comparable manner in the crypts of control and VilCreER ${ }^{T 2}$; Rpap $3^{\text {flox/flox }}$ mice until day 8 (Figs. 3c, 4d). Altogether, these observations confirmed that the loss of Rpap3 induces the rapid disappearance of proliferating stem cells and progenitors, but not of differentiated Paneth cells.

Interestingly, we observed cells with round, dense nuclei, resembling apoptotic cells, in the crypts of small intestines deficient for Rpap3. We verified this by immunostaining for cleaved caspase 3, a well-established marker of apoptosis. In control mice, few cleaved caspase 3-positive cells were visible at the tip of some villi, where they are normally shed. We detected significantly more cleaved caspase $3^{+}$cells in the crypts of tamoxifen-injected VilCreER ${ }^{T 2}$; Rpap3flox/flox mice (Fig. 4e). These apoptotic cells were observed in the crypts and TA compartment, but not at the villi tips, as observed in normal epithelia (Fig. 4f). Thus, Rpap3 deletion eventually induces apoptosis of CBC stem cells and progenitors.

Rpap3 stabilizes clients of diverse families. A prominent R2TP client is Rpb1, the largest subunit of RNA polymerase II (RNA PolII) ${ }^{19,20}$. R2TP incorporates neo-translated Rpb1 within RNA PolII in the cytoplasm, after which it is imported into the nucleus ${ }^{19}$. As expected, immunohistochemistry (IHC) for Rpb1 displayed a nuclear staining in control intestines (Fig. 5a). In VilCreER ${ }^{T 2}$; Rpap $3^{\text {flox/flox }}$ animals, 6 days after the first tamoxifen injection, when the epithelial architecture was still preserved, Rpb1 accumulated in the cytoplasm of CBCs and TA progenitors, but remained nuclear in differentiated epithelial cells, including Paneth cells (Fig. 5a). This suggested that Rpap3 is necessary to assemble RNA PollI in the proliferative compartment (Fig. 5b).

Misfolded HSP90 clients are usually degraded ${ }^{38}$, so we determined the expression levels of R2TP clients in VilCreER ${ }^{T 2}$;

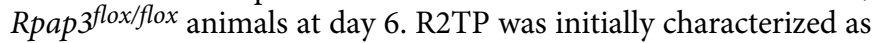
an assembly factor for the box C/D snoRNPs, and in particular it chaperones NOP58, one of the four core proteins in these particles ${ }^{15,39}$. Western blot analysis of crypt cell lysates showed a near twofold reduction of NOP58 levels in extracts from VilCreER ${ }^{T 2}$; Rpap $3^{\text {flox/flox }}$ animals, as compared to controls (Fig. 5c). R2TP stabilizes other non-coding RNPs in HeLa cells, 
a

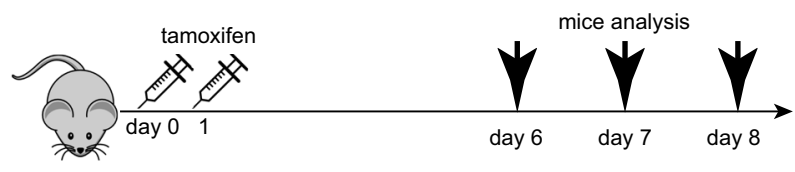

b
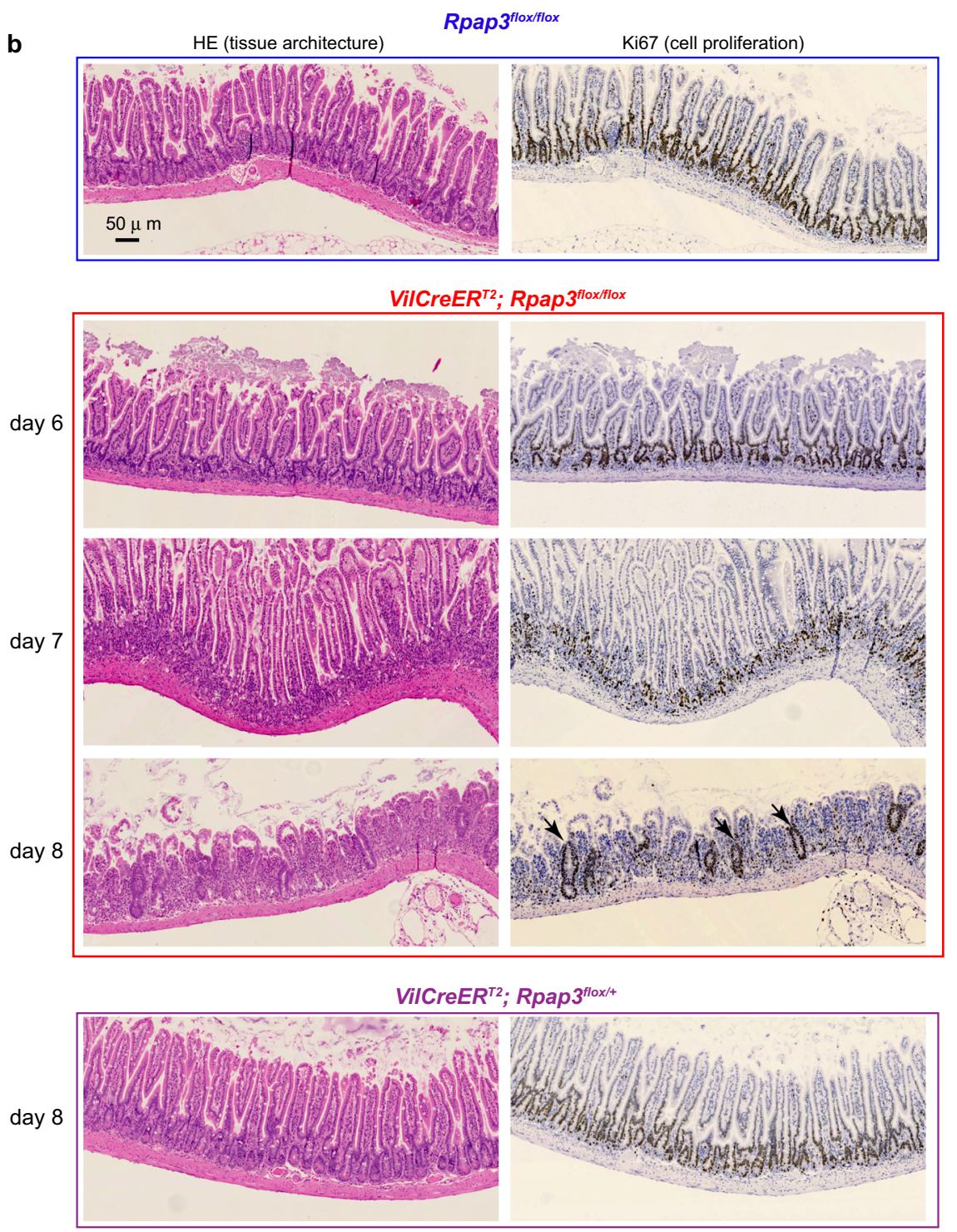

Fig. 2 Rpap3 is necessary to small intestine integrity. a Schematic representation of the experimental setting: 8-week-old mice of the indicated genotype received two sequential injections of tamoxifen $24 \mathrm{~h}$ apart, and were analyzed 6 to 8 days after the first injection. b Pictures of jejunum tissue sections stained with HE (left) or by IHC with anti-Ki67 antibodies (right panels-Ki67 signal is brown) at different days after the first tamoxifen injection. Black arrowheads indicate remnants of crypt glands with $\mathrm{Ki}^{+} 7^{+}$cells observed at day 8 . Scale bar is identical for all panels, and is $50 \mu \mathrm{m}$ as shown in control $\mathrm{HE}$ panel. Each panel is representative of 8 to 12 animals from three independent experiments.

including the U5 snRNP, a splicing ribonucleoparticle that includes the proteins PRPF8 and EFTUD2 ${ }^{17,18}$. Expression of these proteins was reduced by nearly twofold in $\mathrm{KO}$ animals, showing their dependency on R2TP in the small intestine (Fig. 5c). HSP90 and R2TP are thought to stabilize clients only before their assembly, and the extreme stability of snoRNPs and snRNPs may explain this moderate but consistent decrease observed here for their components ${ }^{40}$.

In mammals, PIKKs consist of six structurally related proteins (ATR, ATM, DNA-PK, mTOR, TRRAP, and SMG1). PIKKs are stabilized by the trimeric co-chaperone TTT $^{32,41-43}$ and in murine fibroblasts, TTT recruits R2TP to assemble PIKKs with their partners ${ }^{22}$. By Western blot, we observed again a strong diminution of ATR and ATM, the primary sensors of DNA damage, as well as of mTOR, which activates translation and cell proliferation in response to nutriment availability (Fig. 5d). These results show that R2TP participates in the stabilization of ATR, ATM, and mTOR. Yet, staining for $\gamma \mathrm{H} 2 \mathrm{AX}$, a marker of DNA damage, was similar in control and KO tissues (Supplementary Fig. 3a). In contrast to the other PIKKs, TRRAP level did not vary, either because R2TP does not chaperone TRRAP or because it is a very stable protein.

Interestingly, in control tissues, these R2TP substrates are concentrated in the crypts rather than in the villi. This was observed for the U3 box C/D snoRNP (Supplementary Fig. 3b) and components of the U5 snRNP, as well as ATR 
a

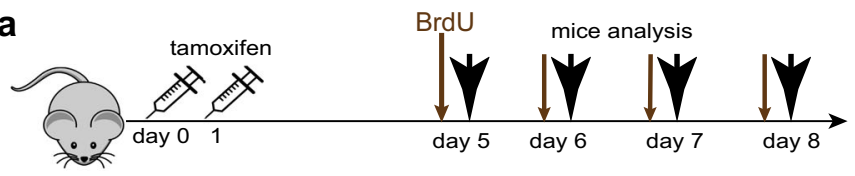

Rpap3 $^{\text {flox/flox }}$

VilCreER ${ }^{\text {T2; }}$ Rpap3 $3^{\text {flox/flox }}$ b

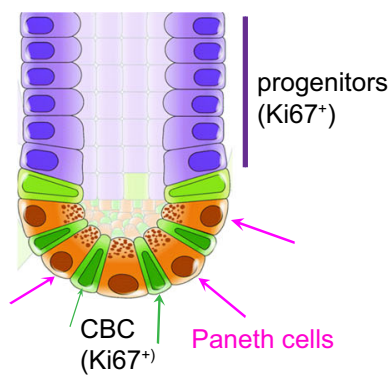

Rpap3 $3^{\text {flox/flox }}$

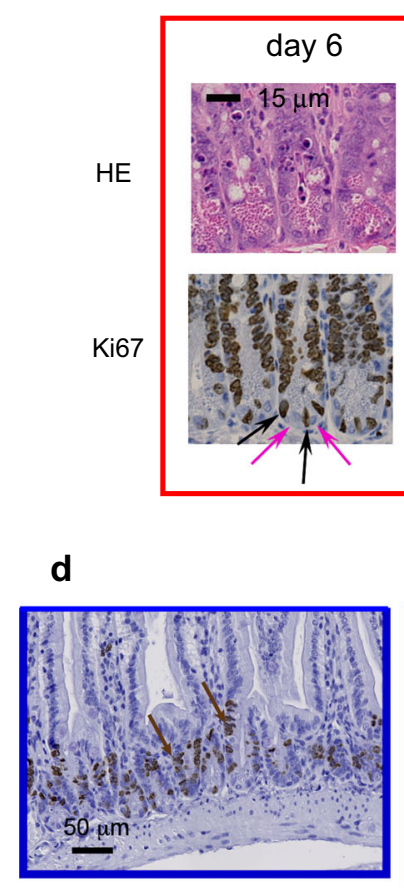

day 5
VilCreER ${ }^{T 2}$; Rpap3 $3^{\text {floxfllox }}$

day 7
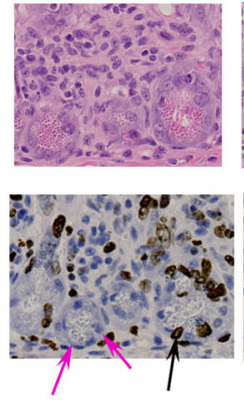

day 8
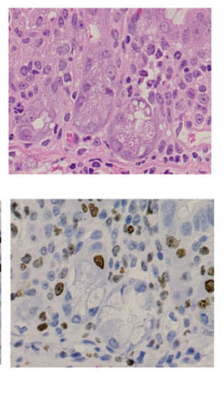

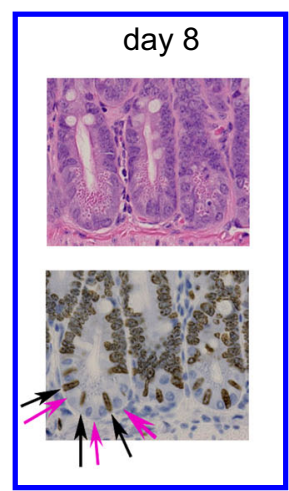

d

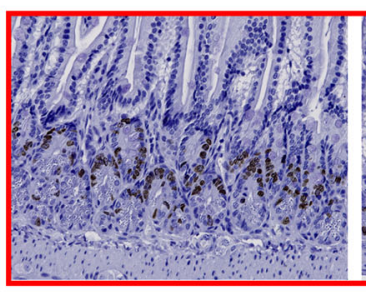

day 5

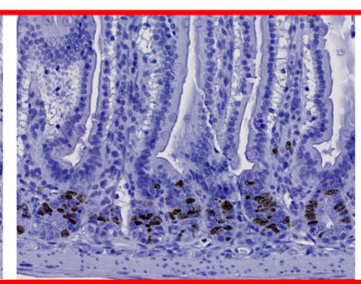

day 6

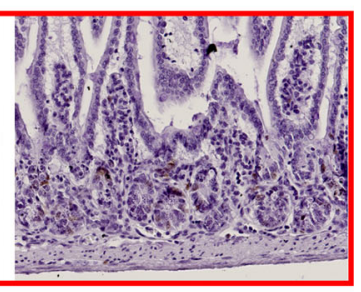

day 7

e

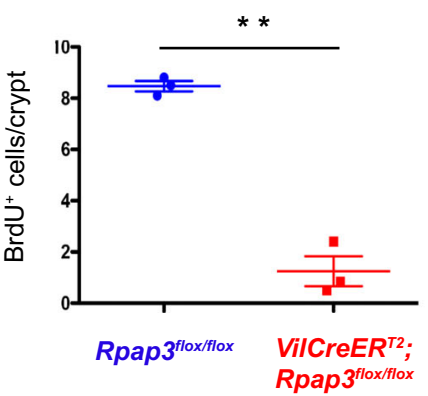

(Supplementary Fig. 3c). Altogether, these data suggest that R2TP assembles cellular machineries mainly in the $\mathrm{CBCs}$ and progenitors.

R2TP KO triggers p53-dependent and independent apoptosis. Cell stress, including DNA damage and ribosome biogenesis defects, stabilize p53, which in turn arrests cell cycle and induces apoptosis. We observed a strong increase of p53 levels at day 6 in the crypts and TA compartment of KO mice (Fig. 6a, Supplementary Fig. 4a). Mutually exclusive staining for p 53 or lysozyme confirmed that the induction of p53 occurs in $\mathrm{CBCs}$ and progenitors but not in Paneth cells (Fig. 6b and Supplementary Fig. $4 b)$.

To address the role of p53 in epithelium degeneration following the loss of R2TP activity, we generated double KO VilCreER ${ }^{T 2}$; Rpap $3_{\text {flox/flox; }}$ Trp $53^{\text {fox }}$ flox mice. We verified that adding floxed alleles did not alter the kinetics of Rpap3 recombination, which was already detected $16 \mathrm{~h}$ after tamoxifen injection (Supplementary Fig. 4c). Accordingly, the phenotype of Rpap3 deletion was unaffected by hemizygous deletion of Trp53 as VilCreER $R^{T 2}$; Rpap $3^{f l o x} / f l o x ; \operatorname{Trp} 53$ flox/+ mice phenocopied VilCreER ${ }^{T 2}$; Rpap $3^{\text {flox/flox }}$ Trp $53^{++}+$mice (hereafter referred to as "Rpap3 KO"). As reported before, invalidation of $\operatorname{Tr} p 53$ alone did 
Fig. 3 Rpap3 is required for proliferation in the small intestine. a Schematic representation of the experimental setting: 8-week-old mice of the indicated genotype received two sequential injections of tamoxifen $24 \mathrm{~h}$ apart, and were analyzed 5 to 8 days after the first injection. $2 \mathrm{~h}$ before each sacrifice, BrdU was injected intraperitoneally to detect cells in S-phase (thin arrows). b Schematic representation of a crypt from the small intestine, with CBC stem cells (in green) sandwiched between Paneth cells (in brown) and progenitors forming the TA on top (purple). c Representative pictures of jejunum tissue sections stained with HE (top) or by IHC with anti-Ki67 antibody (bottom, Ki67 signal is brown) at indicated days after the first tamoxifen injection. Pink arrows point towards Paneth cells and black arrows towards CBC stem cells. Scale bar is shown in control HE panel. Each panel is representative of 8 to 12 animals analyzed in three independent experiments. Scale bar is identical for all panels and is $15 \mu \mathrm{m}$. $\mathbf{d}$ Representative pictures of jejunum taken from control (boxed in blue) and VilCreER ${ }^{T 2}$; Rpap3flox/flox animals (boxed in red), stained by IHC with anti-BrdU antibodies (brown arrows). $n=3-6$ animals/ time point from two independent experiments. Scale bar is shown in control panel and is $50 \mu \mathrm{m}$. e Graph shows mean number of BrdU+ cells/crypt in controls and VilCreERT2; Rpap3flox/flox animals at day 7. Each point represents the average number of BrdU+ cells calculated in $n>35$ crypts from two different zones per animal $(n=3)$. Mean values with S.E.M are indicated for each experimental group. Unpaired two-tailed $t$ test with Welch's corrections $(t=11.66, \mathrm{df}=2)$ indicates significant difference between control and VilCreER ${ }^{T 2}$; Rpap3 $3^{\text {flox }} /$ flox animals $(p=0.0073 ; n=3)$. Source data are provided as a "Source Data file".

not cause any noticeable phenotype $\mathrm{e}^{44,45}$ (Fig. $6 \mathrm{c}$ and Supplementary Fig. 6d). However, double $\mathrm{KO}$ mice showed a transient rescue. At day 6, the intestinal epithelium from VilCreER ${ }^{T 2}$; $R p a p 3^{\text {flox/flox; }} \operatorname{Trp5} 53^{f o x} / f l o x$ mice appeared normal, with regular Ki67 crypt staining, unlike that of Rpap3 single KO mice (Fig. 6c). At day 7, the epithelium from double $\mathrm{KO}$ mice started shrinking, with partial loss of Ki67 staining, while that of single Rpap3 KO mice were strongly disorganized (Fig. 6c). Finally, at day 8, the epithelium from both single Rpap3 and double KO showed similar strong villus blunting (Fig. 6c). Staining for p53 and Rpb1 confirmed the near total penetrance of Trp53 and Rpap3 deletion (Supplementary Fig. 4d and Fig. 6d). We detected cleaved caspase 3 and typical round apoptotic cells in both the double Trp53; Rpap3 KO and the single Rpap3 KO crypts, but not in control nor p53 KO crypts (Fig. 6e). Altogether, these results show that inactivation of Rpap3 induces p53 expression, cell cycle arrest and apoptosis. Still, sustained defective R2TP activity results in epithelium degeneration even in absence of $\mathrm{p} 53$.

Rpap3 functions in the colon as in the small intestine. Depletion of the Rpap3 protein was effective in both the small intestine and the colon (Fig. 1d). Yet, colons were not shorter in Rpap3 KO mice (Fig. 1f), nor was their architecture modified until day 8, as observed by staining with Periodic Acid Schiff (PAS), Ki67, BrdU, and CD44v6 labeling of colonic stem cells ${ }^{46}$ (Fig. 7a and Supplementary Fig. 5a, b). We analyzed R2TP chaperone activity in the colon by performing Western blots. This revealed a small diminution of R2TP substrates in the colon, mostly visible for mTOR and ATM. This diminution was less pronounced than that in the small intestine (Fig. 7b and Supplementary Fig. 5c). It was not accompanied by any detectable accumulation of Rpb1 in the cytoplasm (Supplementary Fig. 5d), nonetheless p53 was induced at the bottom of the crypt, as well as apoptosis (Fig. 7a, c and Supplementary Fig. 5e). This suggests that the small defects occurring in the colon are sufficient to trigger p53 activation, but not to induce a visible phenotype at the tissue level.

To analyze the role of R2TP in the differentiation of the small intestine and the colonic crypts, we simultaneously generated organoids from both tissues, using mice treated with tamoxifen to delete Rpap3, as previously described ${ }^{47}$. Crypts prepared from control small intestines grew to form organoids that budded after $72 \mathrm{~h}$ in culture. In contrast, organoids prepared from KO mice degenerated from $48 \mathrm{~h}$ on, with no observable budding, confirming the essential role of Rpap3 for the survival and differentiation of the small intestinal crypts (Fig. 7d). In parallel, control colonic organoids started differentiating at $72 \mathrm{~h}$ and budded after $96 \mathrm{~h}$ in culture. Remarkably, colonic organoids from Rpap3 $\mathrm{KO}$ mice also died without reaching the budding stage, at $72 \mathrm{~h}$ (Fig. 7d). Thus, R2TP is necessary for the survival and differentiation of both, small intestinal and colonic organoids.
Rpap3 phenotypes mirrors cellular turnover. To reassess the role of Rpap3 in the colon, we generated Lgr5-EGFP-IRESCreER ${ }^{T 2}$; Rpap $3^{\text {flox/flox }}$ animals (Supplementary Fig. 6a). In these mice, GFP and the tamoxifen-inducible Cre are both under the control of the CBC-specific Lgr5 promoter. This construct has a mosaic expression restricted to a few $\mathrm{GFP}^{+}$crypts $^{48}$, allowing the animals to survive and the comparison of Rpap3-deficient and -expressing crypts in the same intestines. Indeed, tamoxifen treated Lgr5-EGFP-IRES-CreER ${ }^{T 2}$; Rpap3 flox/flox mice did not show any visible physiological alteration and could survive for 3 weeks at least. Co-staining for GFP and Rpb1 showed that, at day 7 , in the small intestine, Rpb1 accumulated in the cytoplasm of $\mathrm{CBC}$ stem cells and progenitors from $\mathrm{GFP}^{+}$crypts, but not in $\mathrm{GFP}^{-}$crypts, nor in non-recombinant $\mathrm{GFP}^{+}$crypts from Lgr5EGFP-IRES-CreER ${ }^{T 2}$; Rpap $3^{+/+}$control mice (100\% of $\mathrm{GFP}^{+}$ crypts had cytoplasmic Rpb1; Fig. 8b and Supplementary Fig. 6a). At day 10, $\mathrm{GFP}^{+}$crypts had been eliminated from the small intestine of Lgr5-EGFP-IRES-CreER ${ }^{T 2}$; Rpap3flox/flox mice, as expected from ex vivo organoid experiments (Fig. $7 \mathrm{~d}$ ). In the colon, Rpb1 was nuclear in $\mathrm{GFP}^{-}$and $\mathrm{GFP}^{+}$colonic crypts from Lgr5-EGFP-IRES-CreER ${ }^{T 2}$; Rpap $3^{\text {flox/flox }}$ mice at day 7 (Supplementary Fig. 6a, b). At day 10-12, however, Rpb1 accumulated in the cytoplasm of CBC stem cells and progenitors of $\mathrm{GFP}^{+}$crypts, but not in $\mathrm{GFP}^{-}$and $\mathrm{GFP}^{+}$crypts from control animals (Fig. $8 \mathrm{~b}$ and Supplementary Fig. 6b). Thus, Rpap3 is necessary for Rpb1 biogenesis in both the small intestine and the colon, yet the effect on Rpb1 appears later in the colon than in the small intestine.

To understand the reason for this delay, we compared the cellular turnover between these tissues. For this, we injected the nucleoside analog BrdU as a cell tracer into wild-type mice and sacrificed them subsequently at different time points (Fig. 8c). Two hours after injection, BrdU was incorporated exclusively by $\mathrm{CBC}$ stem cells and progenitors in both the small intestine and the colon (Fig. 8c). After one day, BrdU ${ }^{+}$cells were detectable above the TA compartment in the small intestine, while some remained at the bottom of the crypt. BrdU ${ }^{+}$cells then migrated to the tip of the villus at day 3 , and were eliminated at day 4 , in accordance with the previously described kinetics ${ }^{49}$. In contrast, in the colon, migrating $\mathrm{BrdU}^{+}$cells did not reach the crypt tip before day 4 and were still detectable at day 5 (Fig. 8c). This illustrates a slower cellular turnover in the colon than in the small intestine, which correlates with a slower accumulation of Rpb1 in the cytoplasm of colonic cells, smaller effects on client levels and milder phenotypes at the tissular level (Fig. 7 and Supplementary Fig. 5).

RPAP3 expression correlates with colorectal cancer prognosis. Our results so far suggest an intimate link between R2TP activity and cell proliferation in the intestine. To test if R2TP is also involved in pathogenic proliferation, we took advantage of the CODREAD dataset (available at https://xenabrowser.net/). 
a Olfm4 (CBCs)

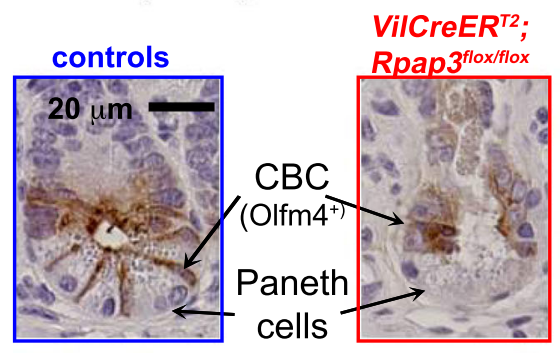

C

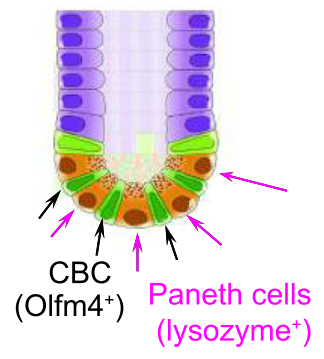

e cleaved caspase 3 (apoptosis) day 6

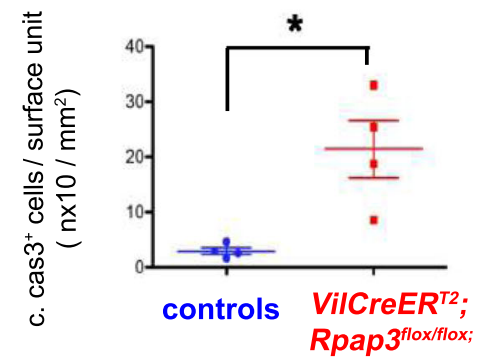

b Olfm4 (CBCs)
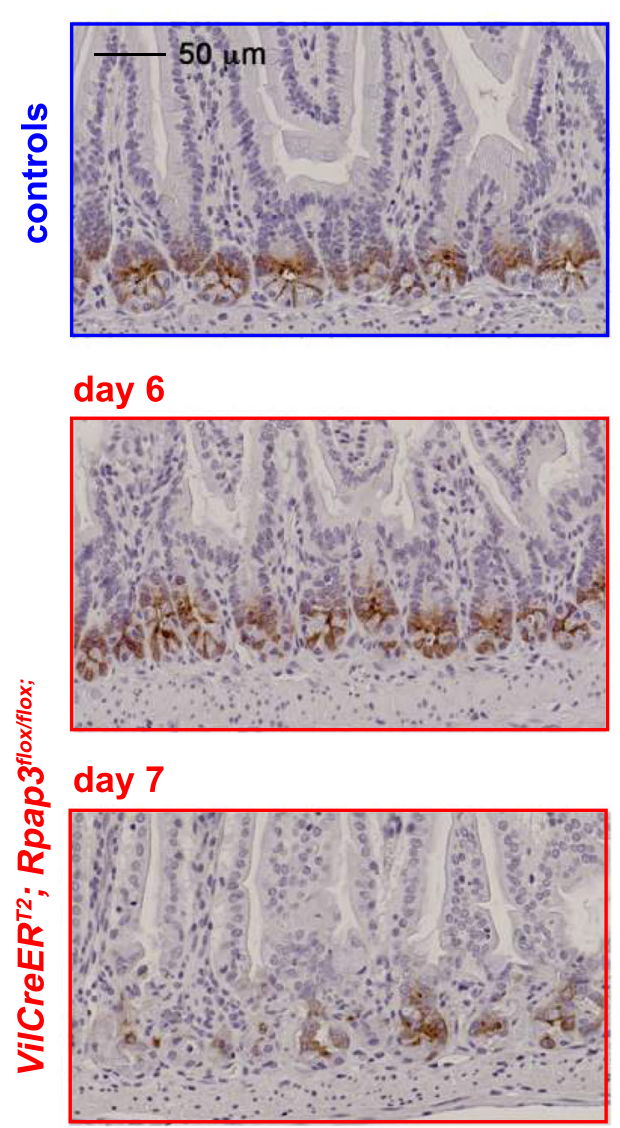

day 8

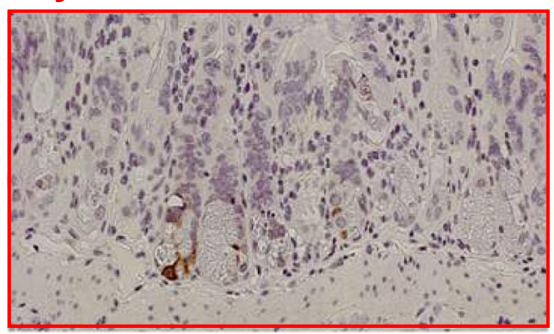

d lysozyme (Paneth cells)
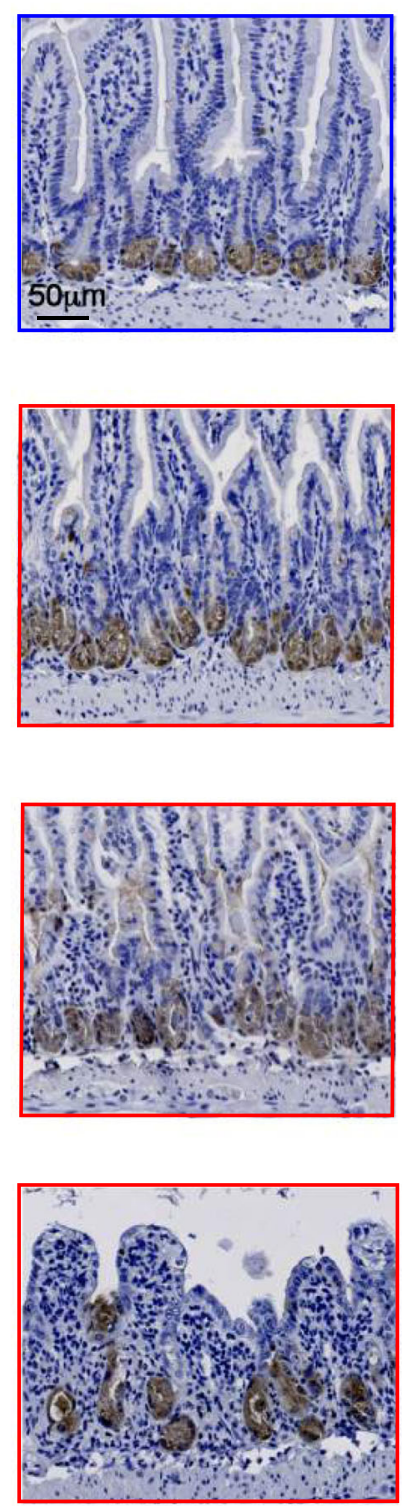

\section{f cleaved caspase 3}
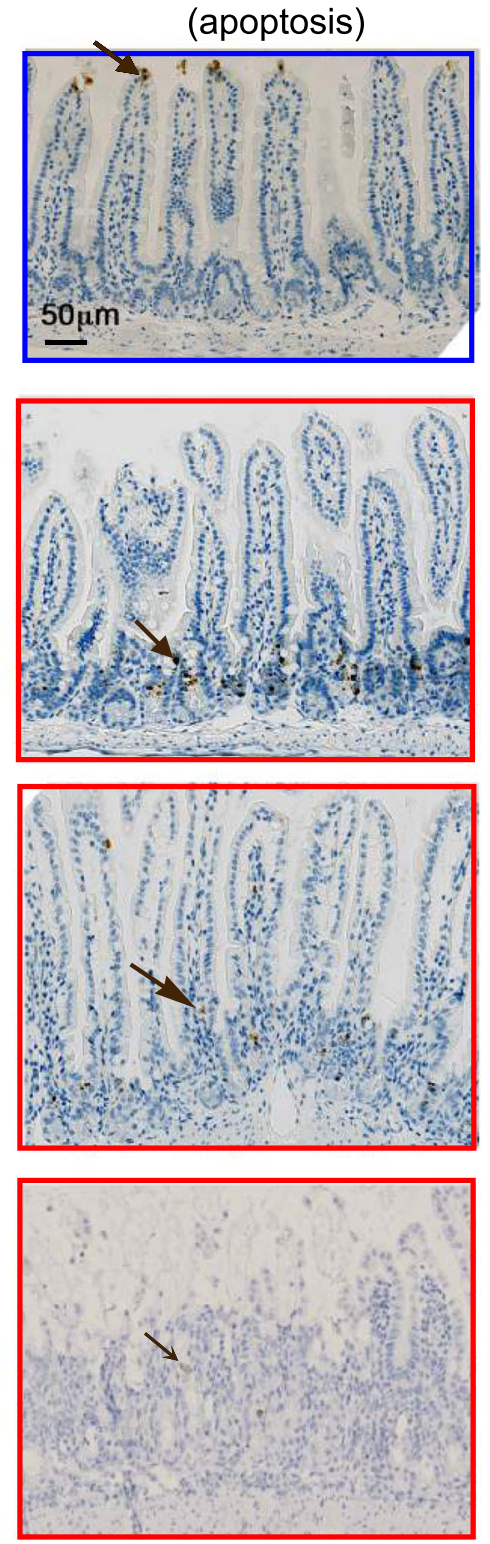

Transcriptomic analyses showed a significant enrichment of mRNAs encoding RUVBL1, RUVBL2, and RPAP3 in human primary colorectal tumors $(n=380)$ as compared to normal tissue $(n=51)$, in agreement with a previous report on a smaller cohort $^{50}$ (Fig. 9a).
This observation prompted us to test the expression of RPAP3 in CRC patient samples, using immunohistochemistry on Tissue Microarrays (TMAs) sections from CRC patients and antiRPAP3 antibodies, which only detects human RPAP3 but not its murine homolog 51 . We analyzed TMAs containing core tissues 
Fig. 4 Rpap3 invalidation induces CBC stem cells loss and apoptosis in the proliferative compartment of the small intestine. a, b Staining for Olfm4 in the jejunum from control (top panel) and VilCreER ${ }^{T 2}$; Rpap3 $3^{\text {flox/flox }}$ animals 7 days (a) or 6 to 8 days after the first tamoxifen injection. Panels are representative for 2 to 4 animals/time point from at least two independent experiments. Scale bar is $20 \mu \mathrm{m}$ in (a) and $50 \mu \mathrm{m}$ in (b). c Schematic representation of a crypt from the small intestine, with CBC stem cells (in green) sandwiched between Paneth cells (in brown) and progenitors forming the TA on top (purple). d Representative micrographs of tissue sections immuno-stained for lysozyme, a specific marker of Paneth cells, in the jejunum of control (top) and VilCreERT2; Rpap3flox/flox mice from day 6 to day 8. Panels are representative for 2 to 3 animals/time point from two independent experiments. Scale bar, identical in all pictures, is $50 \mu \mathrm{m}$. e Total number of apoptotic cells identified by cleaved caspase 3 (cleaved cas $3^{+}$) per surface $\left(\mathrm{mm}^{2}\right)$ of jejunum for each mouse analyzed, at day 6. Mean values with S.E.M are indicated for each experimental group. Unpaired two-tailed $t$ test with Welch's correction indicates significant difference between controls and VilCreERT2; Rpap3flox/flox animals $(p=0.0384 ; t=3.538, \mathrm{df}=3, n=4)$.

f Micrographs are tissue sections stained for cleaved caspase 3 in the jejunum. In control animals, cleaved caspase $3^{+}$cells (brown arrows) are mainly

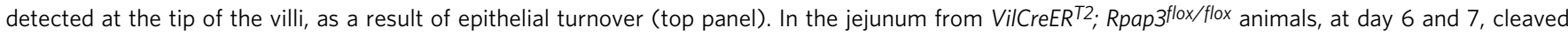
caspase $3^{+}$cells were detected within the crypts (brown arrows). Panels are representative from 2 to 4 animals/time point, from two independent experiments. Scale bar, identical in all pictures, is $50 \mu \mathrm{m}$. Source data are provided as a "Source Data file".

from patients diagnosed with CRC without pathological evidence of nodal involvement and distant metastasis. 157 out of 177 (88.7\%) cases expressed RPAP3 in the tumor cell cytoplasm. The proportion of RPAP3-positive cells was in the range of $4-100 \%$, with a mean \pm S.E. of $62.6 \% \pm 2.6$. To dichotomize the RPAP3 expression level in RPAP3 $3^{\text {high }}$ and RPAP3 ${ }^{\text {low }}$, an optimal cut-off value of $26 \%$ of positive tumor cells was chosen based on the Receiver Operating Characteristic (ROC) analysis $(\mathrm{AUC}=0.593$; Fig. 9b). The relationships between RPAP3 expression and clinico-pathological parameters were investigated by Pearson's $\chi^{2}$ test: RPAP3 expression negatively correlated with the tumor stage of CRC ( $p=0.049$; Supplementary Tables 1, 2). Compared with stage I tumors, the expression of RPAP3 was decreased in stage II tumors $(p=0.049)$. Furthermore, compared with mucinous carcinoma, the expression of RPAP3 was increased in CRC of the adenocarcinoma type $(p=0.025)$. In addition, high RPAP3 expression was positively correlated with the occurrence of tumor relapse $(p=0.003)$ and patients' mortality $(p=0.036)$. Since mTOR can influence CRC outcome ${ }^{52}$, we addressed its contribution by IHC in tumors from the same patient cohort. RPAP3 contributed only to $22 \%$ of mTOR expression level (rho $=0.226, p=0.007$ ), which was not correlated with DFS (Supplementary Fig. 7).

39 out of $123(31.7 \%)$ patients with RPAP3 $3^{\text {high }}$ tumors and 6 out of $54(11.1 \%)$ patients with RPAP3low tumors had disease relapse. Analysis of Kaplan-Meier curves showed that patients with RPAP3 3 high tumors had a lower DFS rate than patients with RPAP3 ${ }^{\text {low }}$ tumors $(p=0.037$; Fig. $9 \mathrm{~b})$. Multivariate analyses of DFS adjusted for other prognostic factors confirmed that RPAP3 expression was a significant prognostic parameter influencing disease relapse $(\mathrm{HR}=2.7: 95 \% \mathrm{CI}, 1.2-6.5 ; p=0.023$; Supplementary Table 3 ), but not the overall survival (OS) of patients. These results provide evidence that high RPAP3-expression levels in CRC tissues are associated with poor patient prognosis.

\section{Discussion}

Since its discovery in 2005, biochemical and structural studies highlighted a chaperoning role for $\mathrm{R}^{2} \mathrm{TP}^{1,3}$. RPAP3 is a central subunit within R2TP: it recruits the chaperones HSP70/90 via its TPR domains, PIH1D1 through a short peptide domain and the $\mathrm{AAA}+\mathrm{ATPases}$ RUVBL1/2 via its C-terminal domain ${ }^{7,10-12}$. Overall, R2TP appears as a central hub for assembling multisubunit complexes by coordinating the activity of HSP70/90 with that of RUVBL1/2. Most of the R2TP clients known so far have been identified in mammalian cell lines ${ }^{4,15,17-20}$ and here we validated several of them in the intestinal epithelium. This includes PRPF8, part of the U5 spliceosomal snRNP, and NOP58, a core component of box C/D snoRNPs required for ribosomal biogenesis. Another class of R2TP substrates are the PIKKs ${ }^{22}$. Several studies have documented that these large proteins are stabilized by a trimeric adaptor called TTT, which itself interacts with R2TP/HSP906,22,32,42,43,53. We show here that mTOR, ATR and ATM depend on Rpap3 in intestinal crypts. Finally, a major R2TP client is RNA PolII. This key enzymatic complex is assembled in the cytoplasm prior to its nuclear translocation ${ }^{19}$. The observed cytoplasmic accumulation of Rpb1 in Rpap3 KO cells thus likely illustrates a defective assembly of RNA PolII.

Remarkably, invalidation of Rpap3 triggers p53 stabilization, cell cycle arrest, apoptosis and destruction of the intestinal epithelium. Transcription inhibition, DNA damage and defects in ribosome biogenesis all activate p53 $3^{54-57}$, yet p53 induction was observed before any detectable alteration in R2TP client activity, such as DNA damage (as monitored by $\gamma \mathrm{H} 2 \mathrm{AX}$; Supplementary Fig. 3a). This was even more striking in the colon, where p53 was activated while R2TP clients were only mildly affected (Fig. 7). Indeed, at day 6 and 7, p53 removal rescued the alterations in small intestine, further showing that, at this point, loss of R2TP client per se was not deleterious. To explain this result, we hypothesize that unassembled R2TP clients trigger p53 activation. For instance, exposed protein surfaces that are normally buried into complexes could sequester the p53-E3 ligase MDM2, as observed for unassembled ribosomal proteins ${ }^{58}$. And indeed, a subset of ribosomal proteins was recently shown to bind Rpap $3^{59}$. These ribosomal proteins could trigger p53 activation following Rpap3 deficiency. In any case, the rescue of the Rpap3 KO phenotype by $\operatorname{Trp} 53$ removal was only transient. Defects in ATR, RNA PolII, snoRNPs, and ribosome biogenesis might induce p53independent apoptosis and lead to small intestine degradation, as described for ATR $^{60}$ and proteins involved in housekeeping cellular mechanisms such as transcription and translation ${ }^{61}$.

Ex vivo experiments showed that crypts from both small intestine and colon depended on Rpap 3 to form organoids, confirming the essential role of Rpap3 in proliferating cells. Interestingly, we found that differentiated cells in the small intestine are barely affected by Rpap3 removal, in contrast to the rapidly dividing CBC stem cells and TA progenitors. Indeed, Rpb1 accumulates in the cytoplasm of proliferating cells, while it remains fully nuclear in the differentiated cells of the epithelium. We propose that $\mathrm{R} 2 \mathrm{TP}$ preferentially assembles the basic cellular machineries in the proliferative compartment: $\mathrm{CBC}$ stem cells and progenitors (Fig. 9c). Indeed, the high division rate of TA and $\mathrm{CBC}$ stem cells $(\sim 10-12 \mathrm{~h})$ likely requires high rates of protein synthesis, folding and assembly, and accordingly, high R2TP activity ${ }^{62}$. In contrast, non-dividing differentiated cells may rely on the preexisting machineries. Indeed, in Hela cells, many R2TP clients (NOP58, PRPF8, EFTUD2, ATR, and mTOR) have an half-life that is too stable to be measured $(>24 \mathrm{~h})^{63}$. Additional data support this model of a preferential role of R2TP in proliferating cells. First, $\mathrm{R} 2 \mathrm{TP}$ is concentrated in CBC stem cells and progenitors of the small intestine. Second, several R2TP clients are more abundant in 

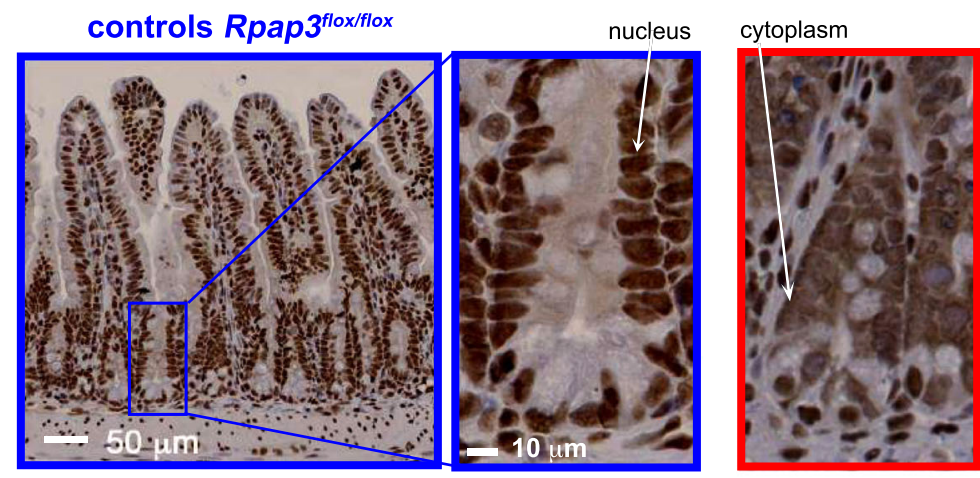

VilCreER ${ }^{T 2} ; \operatorname{Rpap}^{\text {flox/flox }}$

b
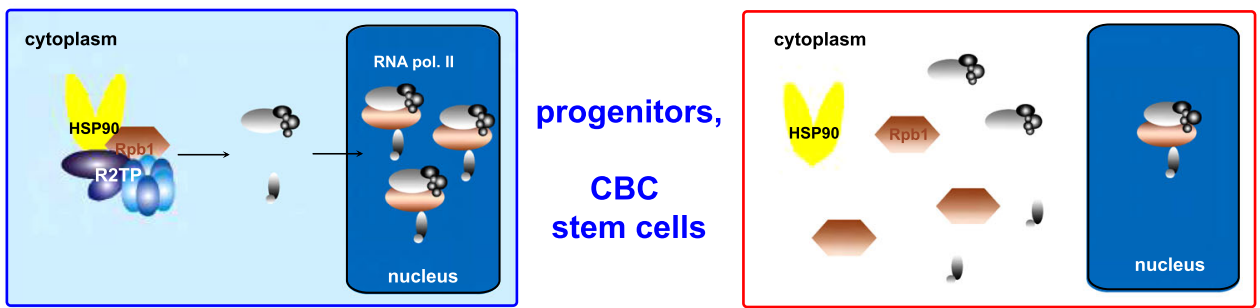

C non-coding RNPs in crypts

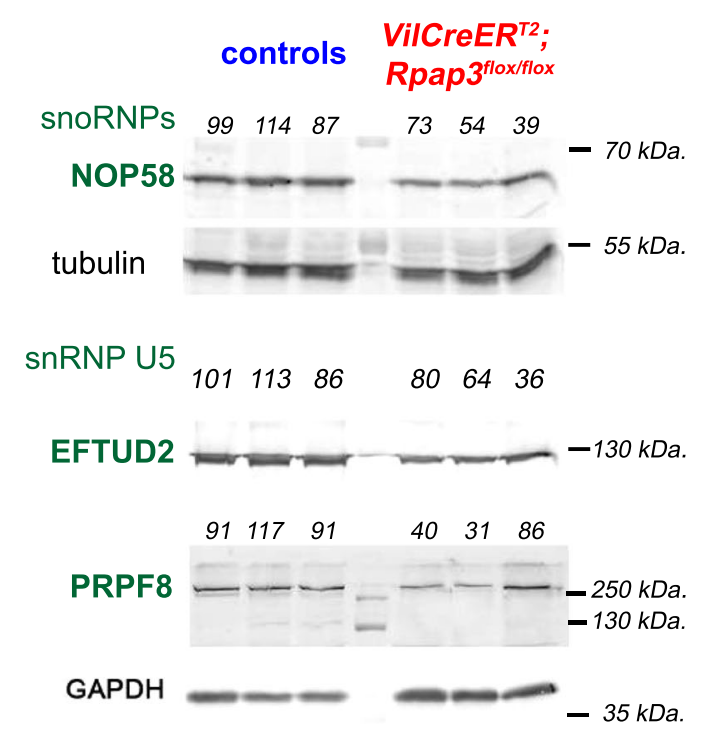

d PIKKs in crypts

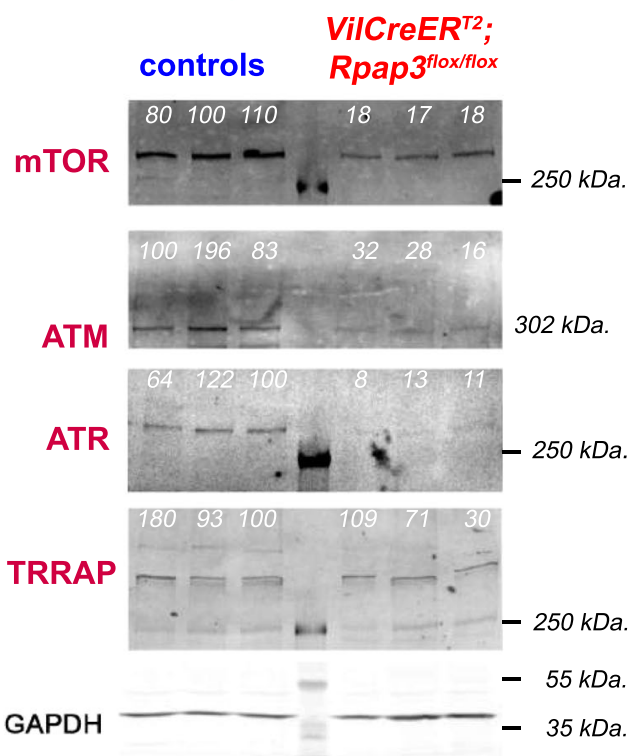

Fig. 5 Rpap3 deletion decreases expression of R2TP clients and leads to cytoplasmic accumulation of RNA polymerase II in intestinal crypts and TA compartment. a Images are tissue sections of small intestines stained by immunohistochemistry (IHC) for Rpb1, the catalytic subunit of RNA polymerase II, from control Rpap3flox/flox mice (blue frame, left panel), or VilCreERT2; Rpap3flox/flox animals at day 6 (red frame, right panel), with magnifications of crypts (scale bars used for the two magnification insets are identical between blue and red frames). Note that the staining in stromal cells is nuclear in both wildtype and VilCreER ${ }^{T 2}$; Rpap3flox/flox animals (stromal cells do not express the Cre) and control epithelium, while it becomes cytoplasmic in the mutant epithelium. Panels are representative for $n=6$ animals from three independent experiments. Scale bar is 50 and $10 \mu \mathrm{m}$ for insets, as shown in control panels. b Schematical interpretation of the micrographs in (a). In control epithelial cells (blue), R2TP incorporates Rpb1 into RNA Polll, which is then imported into the nucleus. In the absence of Rpap3 (red), neo-synthesized Rpb1 accumulates in the cytoplasm. c, d Western blot analysis of preparations enriched for epithelial crypt cells from the jejunum of animals, sacrificed 6 days after the first tamoxifen injection. NOP58, EFTUD2, and PRPF8 (c), mTOR, ATM, ATR, and TRRAP (d) were detected with specific antibodies. Tubulin and GAPDH were used as loading controls. Quantification of the signal ratios are indicated on top of each lane (average for the control ratios was arbitrarily set to 100). Each lane was loaded with the lysate obtained from one animal of the indicated genotype ( $n=3$ per genotype). Similar results were obtained with animals from at least two independent experiments. Apparent molecular weights are indicated on the right. Source data are provided as a "Source Data file". 
a day 6
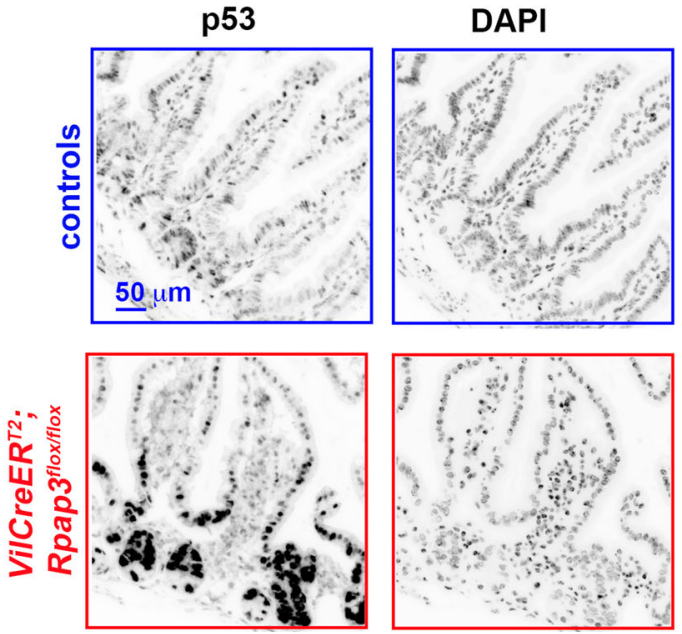

c

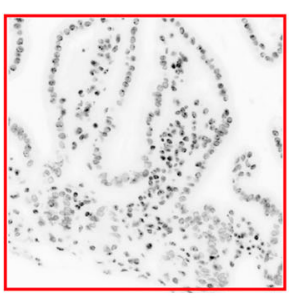

b VilCreER ${ }^{T 2} ; \operatorname{Rpap}^{\text {floxfllox }}$

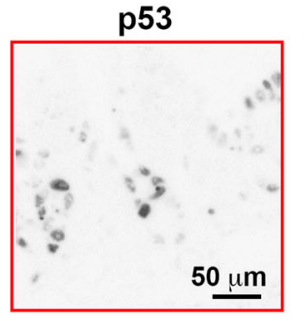

lysozyme
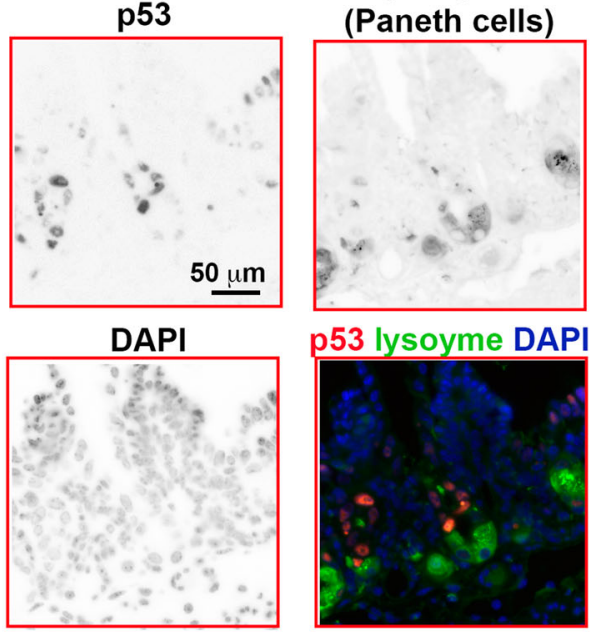

p53 lysoyme DAPI

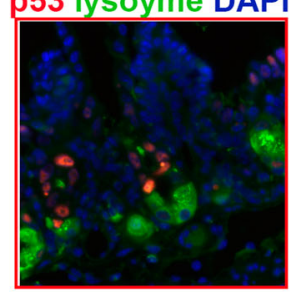

day 7
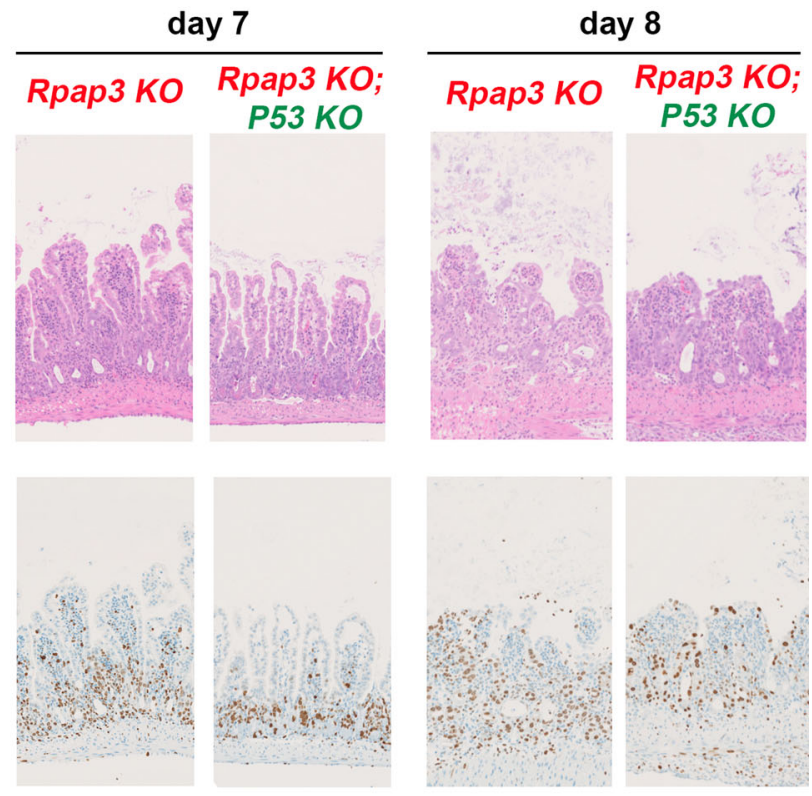

e cleaved caspase 3 (apoptosis) at day 6

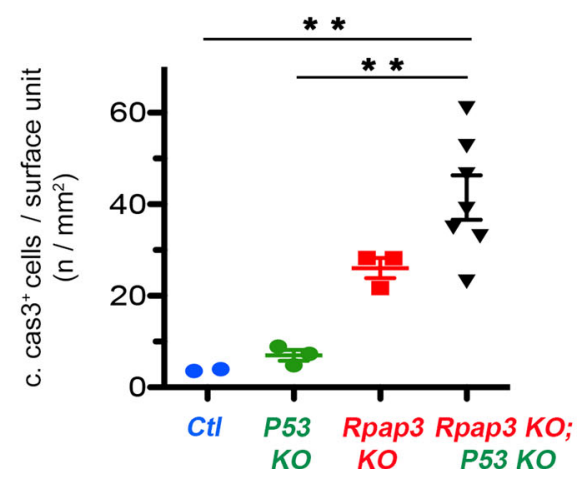

the intestinal proliferative compartment, including ATR, U3 snoRNP and U5 snRNPs (Supplementary Fig. 3b, c). Third, markers of RNA PolI activity, a potential R2TP client, accumulate in the crypts and TA compartment with decreasing levels along the crypt-villus axis ${ }^{56}$. Fourth, a recent transcriptomic analysis along the crypt-villus axis detected mRNAs encoding ribosomal, splicing, and transcription components at the very bottom of the villus, but not along the villus or at the tip ${ }^{64}$.

A correlation between proliferation and sensitivity to Rpap3 removal further extends to the colon. Indeed, R2TP substrates showed milder destabilization in the colon than in the small intestine, while Rpb1 accumulation in the cytoplasm of 
Fig. 6 R2TP invalidation triggers p53-dependent and independent apoptosis. a Micrographs are tissue sections stained for p53 by immunofluorescence in controls (top) and VilCreER ${ }^{T 2}$; Rpap3flox/flox mice (bottom) at day 6, representative of $n=7$ animals from three independent experiments. Nuclei were stained with DAPI. Scale bar is $50 \mu \mathrm{m}$ and is identical for all pictures. b Micrographs are tissue sections stained by immunofluorescence for p53 (Cy5, red) and lysozyme (Alexa 488, green), a marker of Paneth cells, in VilCreER ${ }^{T 2}$; Rpap3flox/flox mice at day $6(n=4)$. Nuclei were stained with DAPI. Scale bar, $50 \mu \mathrm{m}$, is identical for all pictures. c Pictures of jejunum sections stained with HE (top) or by IHC with anti-Ki67 antibodies (bottom) in P53 KO (VilCreER ${ }^{T 2}$; Rpap3flox/+; Trp53flox/flox), Rpap3 KO (VilCreERT2; Rpap3flox/flox; Trp53flox/+) and double Rpap3 KO; P53 KO (VilCreERT2; Rpap3flox/flox; Trp53flox/flox) mice at day 6 to 8 after the first tamoxifen injection. Pictures are representative for each single $\mathrm{KO}(n=3)$ and double $\mathrm{KO}(n=5-7)$ mice, from three independent experiments. Scale bar, $50 \mu \mathrm{m}$, is identical for all pictures. d Pictures of jejunum sections stained by IHC with anti-Rpb1 antibody in control, P53 KO (VilCreER ${ }^{T 2}$; Rpap3flox/t; Trp53flox/flox), Rpap3 KO (VilCreER ${ }^{T 2}$; Rpap3flox/flox; Trp53flox/+) and double Rpap3 KO; P53 KO (VilCreER T2; Rpap3flox/flox; Trp53flox/flox) mice at day 6 following tamoxifen injection. Pictures are representative of $n=3$ for each single KO, $n=7$ for double KO, from two different experiments. Scale bar, $50 \mu$ m, is identical for all pictures. e Total number of apoptotic cells at day 6 per surface $\left(\mathrm{mm}^{2}\right)$ of the jejunum for each mouse analyzed. $n=2$ for wild type, $n=3$ for each single KO, $n=7$ for double KO, from two different experiments. Mean values with S.E.M are indicated for experimental groups with $n>3$. One-way ANOVA analysis $(p=0.0006)$ with Bonferroni's multiple comparison post-test $\left({ }^{\star \star} p<0.001\right)$. Source data are provided as a "Source Data file".

recombinant colonic crypts was detected several days later than in the small intestine. This correlates with the rate of epithelium turnover, which is slower in the colon than in the small intestine (Fig. 8c). In Drosophila, the RPAP3 ortholog, Spag, is required for ovarian Germline Stem Cell (GSC) maintenance, but nor for the surrounding non-dividing cells of the ovary ${ }^{27}$. This exemplifies another case where RPAP3/Spag affects dividing stem cells, and suggests a general role of R2TP in proliferation, especially of active stem cells, across Metazoans.

Tumoral cells are particularly sensitive towards HSP90 inhibition ${ }^{65-67}$. This could be due to HSP90-dependent folding of proteins involved in oncogenic signaling pathways. Furthermore, an enhanced stability of the HSP90 interactome has been described in some tumors and coined the "epichaperome"68. In line with these, invalidation of a cytoplasmic HSP90 paralog essential for spermatogenesis ${ }^{28}$ diminishes lung metastasis in a murine model ${ }^{69}$. Yet, in clinical trials, HSP90 inhibitors have been disappointing, showing cytotoxicity. One reason could be the broad range of HSP90 substrates, which also includes tumorsuppressors ${ }^{70,71}$. To bypass this problem Neckers and Workman suggested to target HSP90 co-chaperones that are specific for a given class of clients ${ }^{72}$. We propose to consider R2TP as a therapeutic target, as a role for R2TP in intestinal carcinogenesis is supported by several lines of evidences: (i) a higher expression of mRNAs encoding R2TP subunits in colorectal tumors, as compared to matching controls, (ii) high RPAP3 protein levels in biopsies of CRC patients with poor diagnostic, (iii) a strong dependency on RPAP3 in the proliferative compartment, and (iv) sensitivity of cell proliferation in a p53-dependent and independent context. R2TP is interesting not only as a therapeutic target but also for prognostic purpose, since R2TP components RPAP3 and PIH1D1 were both identified as part of the epichaperome of HSP90-sensitive tumors ${ }^{68}$.

In conclusion, we show that the R2TP chaperone plays a crucial role in the intestinal epithelium homeostasis by promoting proliferation of stem cells and progenitors (Fig. 9c).

\footnotetext{
Methods

Human colorectal sample collection and analysis. A total of 177 CRCs were collected from patients surgically treated at the University "G. D'Annunzio", Chieti, Italy, between 1996 and 2010. Only the CRC patients who did not receive adjuvant systemic therapy were included in the study. The median follow-up was 53 months (range 3-238 months). During the follow-up, 25.4\% of CRC patients (45 out of 177) had a disease relapse, while deaths were observed in $18.6 \%$ of CRC patients (33 out of 177). Tumor stage was determined according to the American Joint Committee on Cancer TNM staging system (8th edition). Histologically, each CRC case was graded according to the criteria of the WHO classification of tumors of the digestive system (4th edition). Patients and tumor characteristics are summarized in Supplementary Tables 1,2 . The study was reviewed and approved by the Institutional Research Ethics Committee Comitato Etico delle Province di Chieti e Pescara e dell' Università degli studi “G. D'Annunzio" di Chieti e Pescara and written informed consent was obtained from all patients. The study complied
}

with all relevant regulations regarding the use of human study participants, including the criteria set by the Declaration of Helsinki.

TMAs were constructed by extracting 2-mm diameter cores of histologically confirmed neoplastic areas from the 177 CRC cases using a manual Tissue Arrayer (MTA, Beecher Instuments, WI), as previously detailed ${ }^{73}$. It was conducted following REMARK guidelines, as detailed in the REMARK checklist (see Supplementary Note).

Mice generation and treatments. Mouse experiments were performed in strict accordance with the guidelines of the European Community (86/609/EEC) and the French National Committee (87/848) for care and use of laboratory animals, comply the ARRIVE guidelines and were approved by the French Ministry of Higher Education, Research and Innovation (reference APAFIS\#18685) to be performed in the institute animal facility (agreement \# F3417216). Mice were housed in temperature-controlled ventilated cages $\left(20-22^{\circ} \mathrm{C}\right)$ with a $12 \mathrm{~h}$ lightdark cycle, with percentage of humidity between 45 and $55 \%$, and maintained in pathogen-free conditions in the institute animal facility. Rpap $3^{\text {wtsil/ }}\left(\right.$ Rpap $3^{\text {tm } 1 a}$ (KOMP)Wtsi) mice were generated from ES cells (JM8A1.N3, C57BL/6 N genetic background) generated by the trans-NIH KnockOut Mouse Project (KOMP) and obtained from the KOMP Repository (www.komp.org). Genotyping was performed by PCR amplification using primers F5, R5 and R6, on mouse tail genomic DNA (gDNA-Supplementary Fig. 1a). All mice strains Rpap3 $3^{\text {tmla(KOMP)Wtsi, }}$ Tg(CAGflpo)1Afst, Tg(Vill-cre)20Syr, Tg(Vil1-cre/ERT2)23Syr, Lgr5(tm1cre/ERT2)Cle, Trp53 $3^{\mathrm{tm} 1 \mathrm{Tyj} / J}$ (respectively referred to as Rpap3 $3^{\text {wtsi }}$, FlpO, VilCre, VilCreER ${ }^{T 2}, \mathrm{Lgr}^{-}$

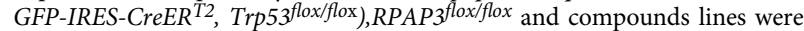
maintained on C57BL/6 background and bred in an SOPF animal facility, and during the experiment in an SPF animal facility. Naive mice were minimum 6 week-old and euthanized by $\mathrm{CO} 2$ and isoflurane. To activate the $\mathrm{CreER}^{\mathrm{T} 2}$, controls and animals of interest received two intra-peritoneal (IP) injection of $2 \mathrm{mg}$ tamoxifen each. For BrdU incorporation assays, mice were intraperitoneally injected with $100 \mu \mathrm{g}$ Bromodeoxyuridine (BrdU) per gram of body weight. The entire small intestine (cut in three parts) and colon were flushed with PBS, then with neutral buffered formalin $10 \%$ and fixed in it for $24 \mathrm{~h}$, dehydrated, and embedded in paraffin.

Histology and immunostainings. TMA tissue sections were stained with a mouse monoclonal antibody raised against RPAP3 (proprietary 19B11 antibody at 1:10 dilution) or an antibody against human mTOR (clone 7C10, 1:100 dilution; overnight incubation; cat. number \#2983; Cell Signaling). Antigen retrieval was performed by microwave treatment at $750 \mathrm{~W}(10 \mathrm{~min})$ in $10 \mathrm{mmol} / \mathrm{l}$ sodium citrate buffer ( $\mathrm{pH}$ 6.0). The polymer kit (EnVision kit, K4003, Agilent) was used for signal amplification. DAB (3,3-Diaminobenzidine) was used as chromogen. Anti-human RPAP3 has been validated and previously published ${ }^{19,51}$. See Supplementary Table 4.

For histological analysis on murine tissues, tissue sections ( $4 \mu \mathrm{m}$ thick) were deparaffinized and rehydrated. They were stained with hematoxylin and eosin (H\&E) or Periodic Acid Schiff staining (PAS) for preliminary analysis. For Ki67, Cleaved-caspase 3 and $\gamma \mathrm{H} 2 \mathrm{AX}$ immunostainings, tissue sections were deparaffinized, rehydrated, and subsequently subjected to heat induced antigen retrieval in $10 \mathrm{mM}$ sodium citrate buffer ( $\mathrm{pH}$ 6) or $10 \mathrm{mM}$ Tris $\mathrm{HCl}-1 \mathrm{mM}$ EDTA buffer ( $\mathrm{pH} 9$ ), depending on the antibody. Immunohistochemistry was performed using a Dako autostainer (Dako, Glostrup, Denmark) by the RHEM facility.

For immunohistochemistry (Rpb1, Lysozyme, Olfm4, Pih1d1), tissue slides were incubated in $10 \mathrm{mM}$ sodium citrate $\mathrm{pH} 6$ (T0050, DiaPATH) or $10 \mathrm{mM}$ Tris $\mathrm{HCl} 1 \mathrm{mM}$ EDTA pH 9 buffer for $20 \mathrm{~min}$ at $100^{\circ} \mathrm{C}$ for antigen retrieval, depending on the antibody. Endogenous peroxidase activity was inactivated with PBS- $-0.3 \%$ hydrogen (\#H1009, Sigma). After blocking in 2.5\% blocking serum-5\% BSA-5\% nonfat milk for $30 \mathrm{~min}$ at room temperature, tissue slides were incubated with primary antibodies overnight at $4{ }^{\circ} \mathrm{C}$. Then corresponding secondary antibody 
a

colons at day 8

PAS controls
Rpap3 $3^{\text {flox } f l o x}$

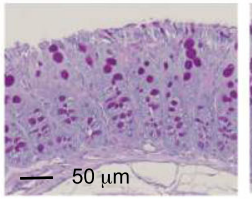

Ki67

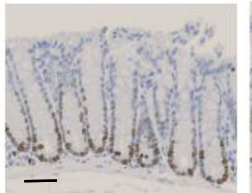

CD44v6

(stem cell marker)

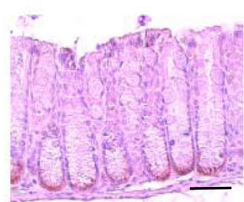

p53

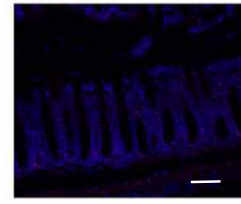

VilCreER ${ }^{T 2}$;

Rpap3 $3^{\text {flox/flox }}$
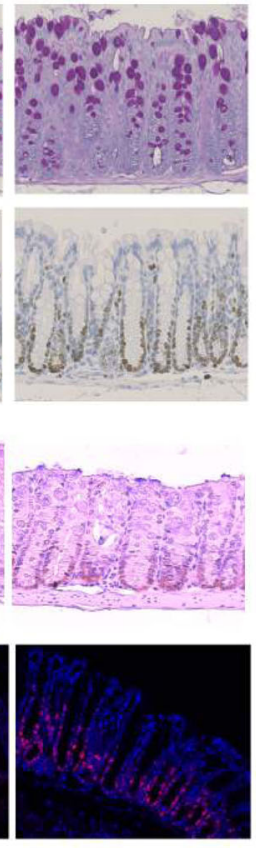

b colonic epithelial cell extracts at day 7

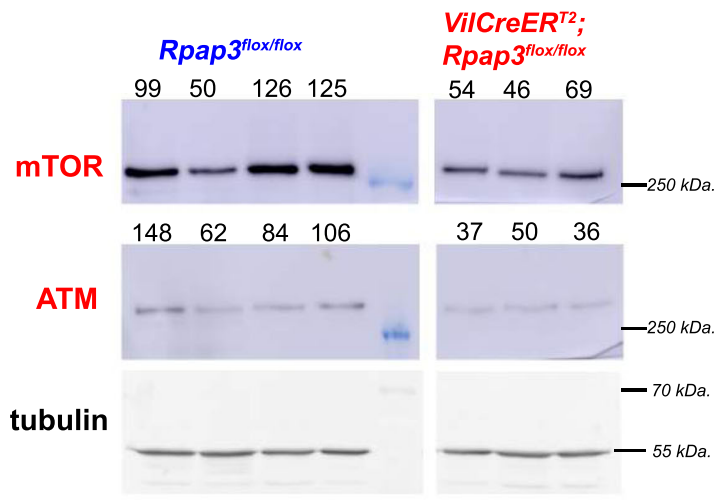

C cleaved caspase 3 at day 8

Ctl

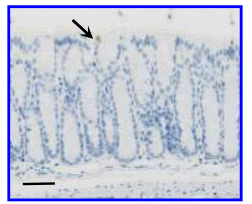

KO
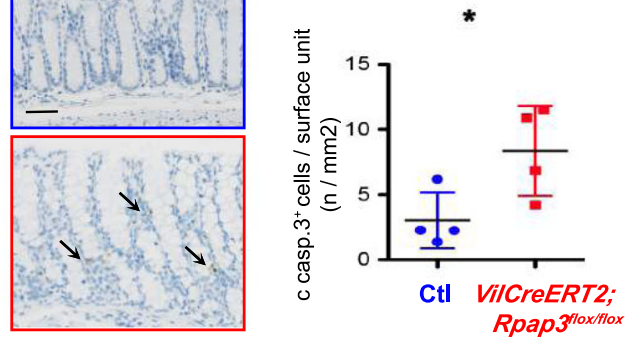

d

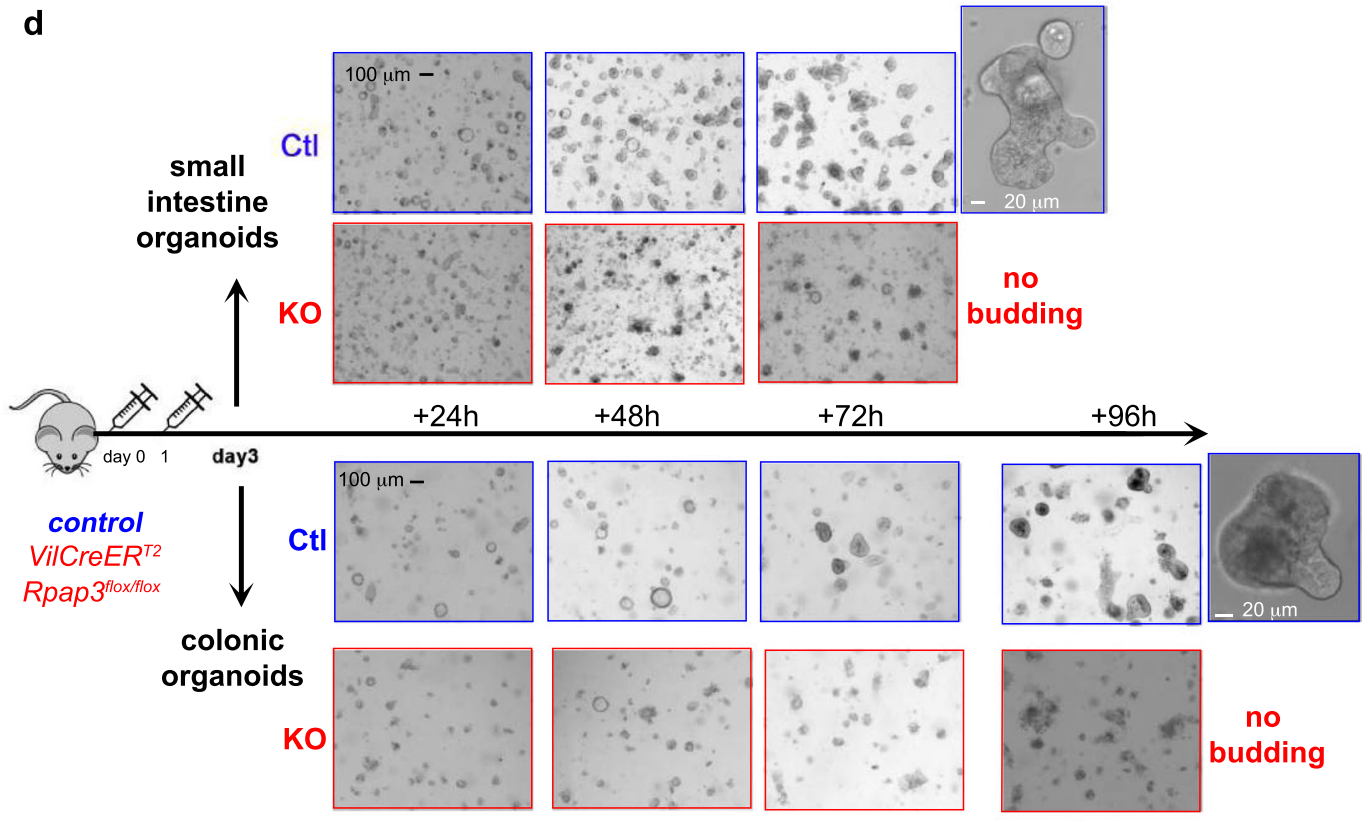

reagents (ImmPRESS ${ }^{\mathrm{TM}}$ kit, Vector Laboratories), directed against mouse, goat or rabbit were used for detection.

Incorporation of $\mathrm{BrdU}$ in proliferating intestinal epithelial cells was detected using an anti-BrdU antibody (Biolegend, 1:100) after deparaffinization of the tissues, antigen retrieval in $10 \mathrm{mM}$ citrate buffer $\mathrm{pH} 6$, as described above, and DNA denaturated using $2 \mathrm{~N} \mathrm{HCl}$ for $1 \mathrm{H}$ at $37^{\circ} \mathrm{C}$ followed by an incubation in $0.1 \mathrm{M}$ borax buffer $\mathrm{pH}$ 9. Revelation was performed using the Avidin/Biotin Vectastain System kit (Vectorlab, USA) according to the manufacturer protocol. After neutralization of the endogenous peroxidase activity, the sections were incubated with the primary antibodies.

Antibody were visualized using the Envision system (Dako). 3,3'-

Diaminobenzidine (Dako) was used as the chromogen and the sections were lightly counterstained with hematoxylin. Histological slides were scanned using the
Nanozoomer 2.0 HT scanner with a $\times 40$ objective, and visualized with the NDP. view2 software (both from Hamamatsu).

For p53 immunofluorescence, paraffin-embedded tissues were cut into $3-\mu \mathrm{m}$ thick sections, mounted on slides, then dried at $37^{\circ} \mathrm{C}$ overnight. Staining was performed on the Discovery Ultra Automated IHC staining system from Roche Ventana. Following deparaffination with the Discovery EZ Prep solution at $75^{\circ} \mathrm{C}$ for $24 \mathrm{~min}$, antigen retrieval was performed at $95^{\circ} \mathrm{C}$ for $16 \mathrm{~min}$ using the Discovery CC1 buffer. After blocking in TBS, $10 \%$ goat serum, $5 \%$ BSA, $5 \%$ milk, $0.3 \%$ triton $\mathrm{X} 100$, the slides were incubated with a rabbit anti-p53 antibody $37^{\circ} \mathrm{C}$ for $60 \mathrm{~min}$ (Leica, P53-CM5P-L, 1:250). Signal enhancement was performed using the OmniMap anti-Rabbit HRP kit (Roche, 760-4457) then with the Cy5 Kit (Roche, 760-238). For double immune-stainings, slides were stripped by heating before incubation with anti-lysozyme antibody. 
Fig. 7 Rpap3 is required in the colon. a Representative micrographs of colon sections stained by Periodic Acid Schiff stain (PAS, for labeling of goblet cells), IHC for Ki67 and CD44v6 (a marker of the colonic stem cells) and IF for p53, in controls Rpap3flox/flox (left) and VilCreER ${ }^{T 2}$; Rpap3 flox/flox mice (right) at day 8 ( $n=4$ from at least two independent experiments). Scale bars are $50 \mu \mathrm{m}$. b Western blot analysis of colonic epithelial cells from animals, sacrificed 7 days after the first tamoxifen injection. mTOR, ATM, and tubulin were detected with specific antibodies. Quantification of the signal ratios are indicated on top of each lane (average for the control ratios was arbitrarily set to 100). Each lane was loaded with the lysate obtained from one animal of the indicated genotype (representative for $n=5 \mathrm{KO}$ animals in one experiment). Molecular weights are indicated on the right. c Micrographs are tissue sections stained by IHC for cleaved caspase 3 in Rpap3flox/flox (blue) and VilCreER $R^{T 2}$; Rpap3flox/flox (red) mice at day 6, representative for $n=4$ from two different experiments. Total number of apoptotic cells at day 8 per surface $\left(\mathrm{mm}^{2}\right)$ of the jejunum for each mouse analyzed. Mean values with S.E.M are indicated for each experimental group. Unpaired two-tailed t test with Welch's correction indicates significant difference between controls and VilCreER ${ }^{T 2}$, Rpap3flox/flox animals $(p=0.0234, t=2.625, \mathrm{df}=5)$. Scale bar is $50 \mu \mathrm{m}$. d Picture of organoids cultures. Crypts from small intestine (top) and colon (bottom) were prepared from Rpap3flox/flox (blue) and VilCreER ${ }^{T 2}$; Rpap3flox/flox (red) mice 3 days after tamoxifen injection ( $n=3$ ). Identical number of crypts were seeded and organoids culture were monitored every day. Organoids from control animals started budding after $72 \mathrm{~h}$ in culture for small intestine crypts and $96 \mathrm{~h}$ for colonic crypts. Organoids generated from VilCreER ${ }^{T 2}$; Rpap3flox/flox animals degenerated in culture before budding. Scale bar are $100 \mu \mathrm{m}$ for all pictures and $20 \mu \mathrm{m}$ for organoid insets. Source data are provided as a "Source Data file".

For Rpb1/GFP immunofluorescence, antigen retrieval with 1 mM EDTA was performed for $30 \mathrm{~min}$ at $99^{\circ} \mathrm{C}$. Slides were blocked with $5 \%$ goat serum-PBS- $0.3 \%$ triton X-100 for $1 \mathrm{~h}$ at RT then incubated with primary antibodies overnight at $4{ }^{\circ} \mathrm{C}$. Samples were incubated in a DAPI solution combined with the secondary antibodies for $1 \mathrm{~h}$ at RT. Slides were mounted with cover slip in ProLong Gold Antifade Mounting media or Vectashield. Fluorescent images were acquired by the Axioscan 40x camera and analyzed with ZEN (both from Zeiss), brightfield upright Zeiss Axioimager Z1 using the Metamorph software, or on the inverted Confocal SP5 (Leica) using the Leica LAS AF software.

All antibodies used for immunostainings are described in Supplementary Table 4 and have been validated by the manufacturers, independent groups (see https://www.citeab.com), the RHEM platform, our previous work (Rpb1) ${ }^{19}$ or this study.

For $\beta$-galactosidase activity, small intestines and colons cryo-preserved were cut to slices of $10 \mu \mathrm{m}$ thickness. Samples were treated with $0.5 \%$ glutaraldehyde for $10 \mathrm{~min}$ at room temperature, followed by $24 \mathrm{~h}$ of incubation at $37^{\circ} \mathrm{C}$ in a staining solution containing $1 \mathrm{mg} / \mathrm{ml} \mathrm{X-gal,} 5 \mathrm{mM}$ potassium ferricyanide $(\mathrm{K} 3 \mathrm{Fe}(\mathrm{CN}) 6)$, $5 \mathrm{mM}$ potassium ferrocyanide $(\mathrm{K} 4 \mathrm{Fe}(\mathrm{CN}) 6)$ and $2 \mathrm{mM} \mathrm{MgCl} 2,0.1 \%$ Triton X100 in PBS. Samples were washed in PBS for 5 min, counterstained with Nuclear Fast Red and briefly rinsed with $\mathrm{dH} 2 \mathrm{O}$ before mounting using an aqueous mounting solution (Aquatex, 108562;Merck)

U3 snoRNA FISH. Small intestines and colons cryo-preserved were cut to slices of $10 \mu \mathrm{m}$ thickness. The frozen sections were fixed in PBS/paraformaldehyde $4 \%$ at room temperature for $60 \mathrm{~min}$, followed by permeabilization with ethanol $70 \%$, overnight at $4 \circ \mathrm{C}$. In situ hybridization was performed overnight with Cy3 labeled oligonucleotides against U3 (AT*AGAACGATTCAACT*CATCAACGCGGGT*G CACTTGGCTTTCT*A).

After several washes, the slides were staining with DAPI and mounted in Vectashield.

Microscopy and imaging. Histological slides were scanned using the Nanozoomer 2.0 HT scanner with a $\times 40$ objective, and visualized with the NDP.view2 software (Hamamatsu). Fluorescent images were acquired with Axioscan using ZEN software (Zeiss), brightfield Axioimager Z1 (Zeiss) using the Metamorph software or on the inverted Confocal SP5 (Leica) using the Leica LAS AF software. Images were processed with Adobe Photoshop CS6.

Isolation of epithelial cells from the intestine. Small intestines and colons were isolated and flushed with cold PBS. Colon and the three intestine fragments were cut open length-wise, then kept in $10 \mathrm{ml}$ cold wash buffer (PBS, 2\% FBS and antibiotics). Tubes were shaken several times to wash the fragments and put into $15 \mathrm{ml}$ falcon tube containing $10 \mathrm{ml}$ CE buffer (PBS, $1 \%$ BSA, $1 \mathrm{mM} \mathrm{DTT}, 1 \mathrm{mM}$ EDTA, $5.6 \mathrm{mM}$ glucose). Tubes were placed on a vertical shaker at $37^{\circ} \mathrm{C}$ for $30 \mathrm{~min}$. After removing tissue, cells were collected by centrifugation at $1410 \mathrm{rpm}$ for $7 \mathrm{~min}$. They were washed in $10 \mathrm{ml}$ wash buffer. Collected cells were split in different tubes and stored at $-80^{\circ} \mathrm{C}$.

To separate villi and crypt cells, after PBS wash, villi were gently scraped off using a glass cover slip. Free villi fractions were collected by pipetting in $1 \mathrm{ml}$ of cold PBS. The rest of tissue (the crypts were still attached) was incubated with $10 \mathrm{ml} \mathrm{CE}$ lysis buffer to dissociate and collect crypt cells.

Organoids. Colons and small intestines were dissected, inverted on a stick, cut longitudinally then washed extensively in cold PBS-supplemented with penicillin/ streptomycin. After cutting them in $0.3 \mathrm{~cm}$ long pieces, they were incubated in $10 \mathrm{ml}$ of cold PBS. Pieces were washed 5 to 10 times in cold PBS with antibiotics and then treated for $30 \mathrm{~min}$ at $4{ }^{\circ} \mathrm{C}$ with PBS-25mM EDTA for the colon and PBS2-mM EDTA for the small intestine. After sedimentation, the pieces were washed four times in $10 \mathrm{ml}$ of cold PBS. For each wash, corresponding to Fraction 1 to 4 , the supernatant was strained in a $70 \mu \mathrm{m}$ mesh filter. Each fraction was then centrifuged at $390 \mathrm{~g}$ for $7 \mathrm{~min}$ and checked for the presence of well-formed crypts under the microscope. Usually fractions 3 and 4 were used for the organoid culture. 200 crypts were resuspended in 50 $\mu \mathrm{l}$ of Matrigel in WENR (DMEM-F12 media supplemented by WNt3a, EGF, Noggin, R-spondin-1) media for the colon and ENR (DMEM-F12 media supplemented by EGF, Noggin, R-spondin-1) media for the small intestine and microscopically inspected once a day, as described ${ }^{47}$.

Western blots. Protein extracts were prepared from epithelial cell preparations by lysis in cold RIPA buffer (50 mM Tris pH8, $150 \mathrm{mM} \mathrm{NaCI}, 1 \%$ NP40, $0.5 \%$ deoxycholate) supplemented with inhibitors. Protein lysates were separated on a gradient $4-15 \%$ SDS-PAGE (BioRad) and transferred to a nitro-cellulose membrane (Amersham Protran $0.2 \mu \mathrm{m} \mathrm{NC}$ ). Membranes were blocked with TBS $-2.5 \%$ nonfat milk $(\mathrm{w} / \mathrm{v})-0.05 \%$ Tween and incubated with the appropriate primary antibodies, followed by an incubation with secondary antibodies conjugated to the horseradish-peroxidase or a fluorophore. ECL was revealed with Amersham ECL 600 camera and fluorescence with the Amersham Typhoon scanner.

Primary antibodies from Cell Signaling: ATM clone D2E2 (CST 2873S) rabbit at 1/1000, ATR clone E1S3S (CST 13934S) rabbit at 1/1000, mTOR (CST 2972S) rabbit 1/1000, p53 clone 1C12 (CST2524S) mouse 1/1000; PRPF8 (sc-30207, Santa Cruz) rabbit 1/200; from Abcam: EFTUD2 (ab72456) rabbit 1/2000, GAPDH (ab8245 6C5) mouse 1/10000; from Sigma: NOP58 (HPA018472) rabbit 1/100, RPAP3 (SAB1411438) rabbit 1/1000, $\alpha$-Tubulin (I2G10) mouse 1/500; from Proteintech PIH1D1 (19425-1-AP) rabbit 1/1000; from Bertin TRRAP (G01043 murine clone 2D5) mouse 1/1000 (a generous gift from L. Tora). We validated anti-PRP8 in ${ }^{17}$ and anti-TRRAP using a proprietary cell line with degradable TRRAP. All other antibodies have been validated by the manufacturers, as well as by independent groups which reported their use in several publications, notably in the CiteAb platform (https://www.citeab.com/) and are described in Supplementary Table 4.

DNA extraction. Samples were incubated in $100 \mu \mathrm{l}$ of alkaline lysis buffer $(\mathrm{NaOH}$ $25 \mathrm{mM}$, EDTA $0.2 \mathrm{mM}$ ) at $92^{\circ} \mathrm{C}$ for $20 \mathrm{~min}$, kept on ice for $10 \mathrm{~min}$. Then $100 \mu \mathrm{l}$ of neutralizing reagent $(40 \mathrm{mM}$ Tris $\mathrm{HCl} \mathrm{pH} \mathrm{5)}$ was added to the samples. $2 \mu \mathrm{l}$ were used for each PCR.

Southern blot. Briefly, ES cells were incubated overnight at $65^{\circ} \mathrm{C}$ in $100 \mathrm{mM}$ Tris $\mathrm{HCl} \mathrm{pH8.8-5} \mathrm{mM} \mathrm{EDTA-0.2 \%} \mathrm{SDS-} 200 \mathrm{mM} \mathrm{NaCl}$ with $0.1 \mathrm{mg} / \mathrm{ml}$ proteinase $\mathrm{K}$ in a humid chamber. On the following morning, lysates were extracted twice with phenol $\mathrm{pH} 7.0-8.0$ and once with chloroform then precipitated in $\mathrm{NaCl} / \mathrm{EtOH}$. Following recovery, $10-15 \mu \mathrm{g}$ of genomic DNA were digested for 24 to $48 \mathrm{~h}$ with appropriate highly concentrated restriction enzymes (40-50 U/ $\mu \mathrm{l}-10 \mathrm{U} / \mu \mathrm{g}$ of gDNA). The analysis was performed by Southern blot as described in $^{74}$.

PCR for genotyping. Initial denaturation: $95^{\circ} \mathrm{C}(2 \mathrm{~min})$, Denaturation $95^{\circ} \mathrm{C}(30 \mathrm{~s})$, Annealing $55^{\circ} \mathrm{C}(45 \mathrm{~s})$, Extension $72^{\circ} \mathrm{C}(45 \mathrm{~s})$, and Final extension: $72^{\circ} \mathrm{C}(2 \mathrm{~min})$ for 35 cycles. Primers: RPAP3: F5 (GGTGCCACAGTGTGAGTG), R5 (TGCC TCCTGACTCACTACAG, R6 (ACCGTGTCGCTACGTCACTGCG); CREERT2-F (TTACGGCGCTAAGGATGACT), CREERT2-R (AAGGCCAGGCTGTTCTT CTT); P53-F (TGC TAG ATG CTT AGG GCT GC), P53-R (GAC TGG CCC TTC TTG GTC TT). Primers are reported in the Supplementary Table 5.

Statistical analysis. Transcriptomic analysis of R2TP subunits in human samples were extracted from the CODREAD cohort available at UCSC Xena platform for 

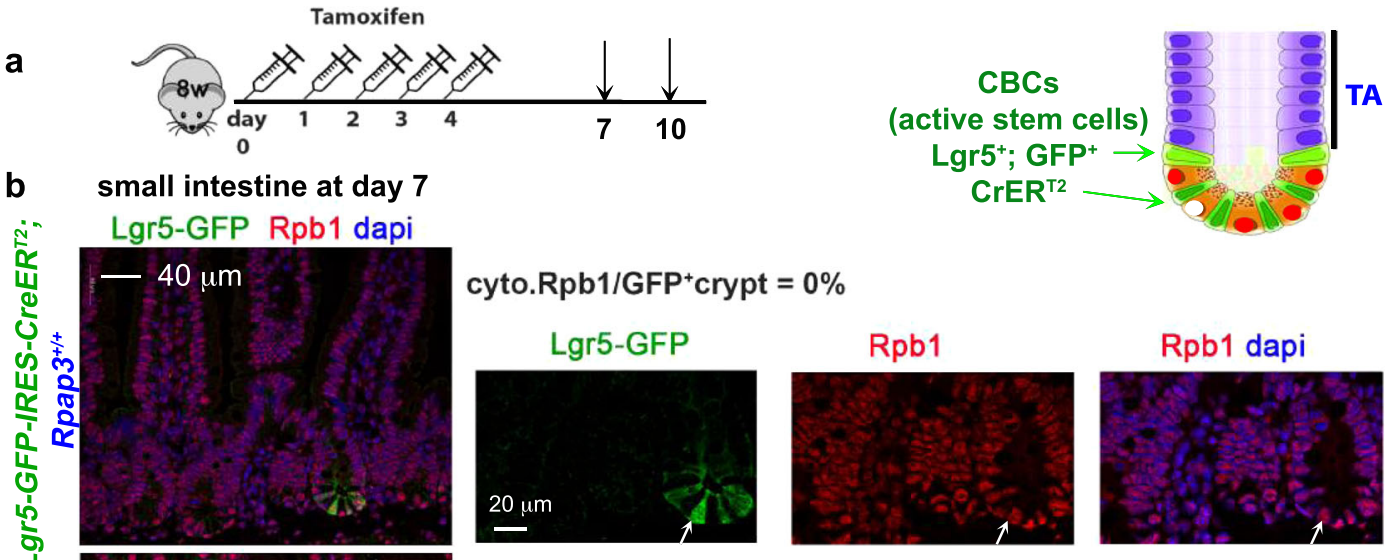

cyto.Rpb1/GFP ${ }^{+}$crypt $=0 \%$

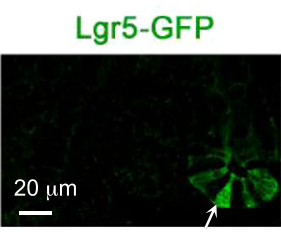

Rpb1

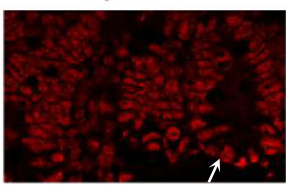

Rpb1 dapi

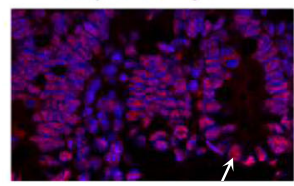

cyto. Rpb1/GFP ${ }^{+}$crypt $=100 \%$
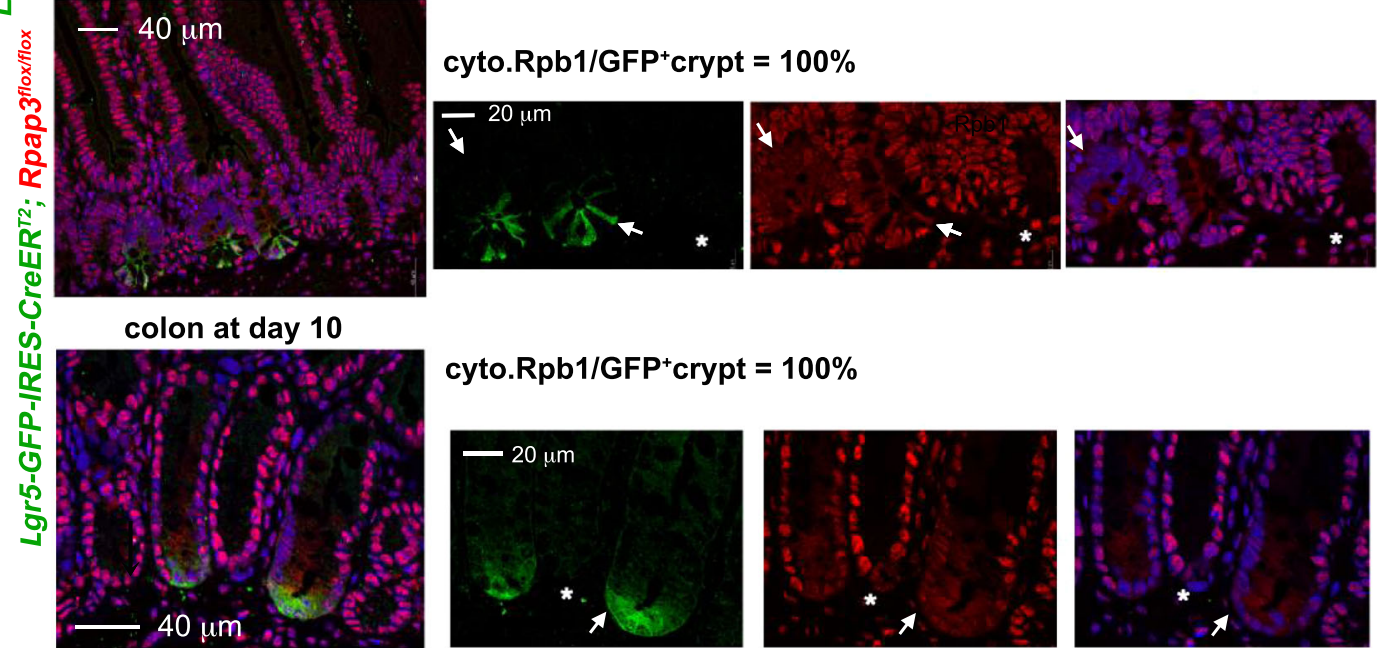

cyto. $\cdot$ ppb1/GFP ${ }^{+}$crypt $=100 \%$

C
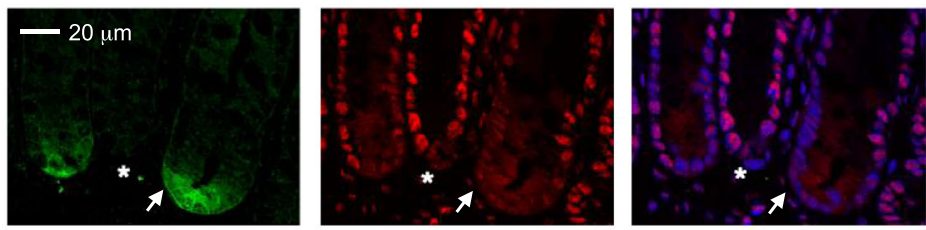

$$
\text { Brdu } \downarrow
$$
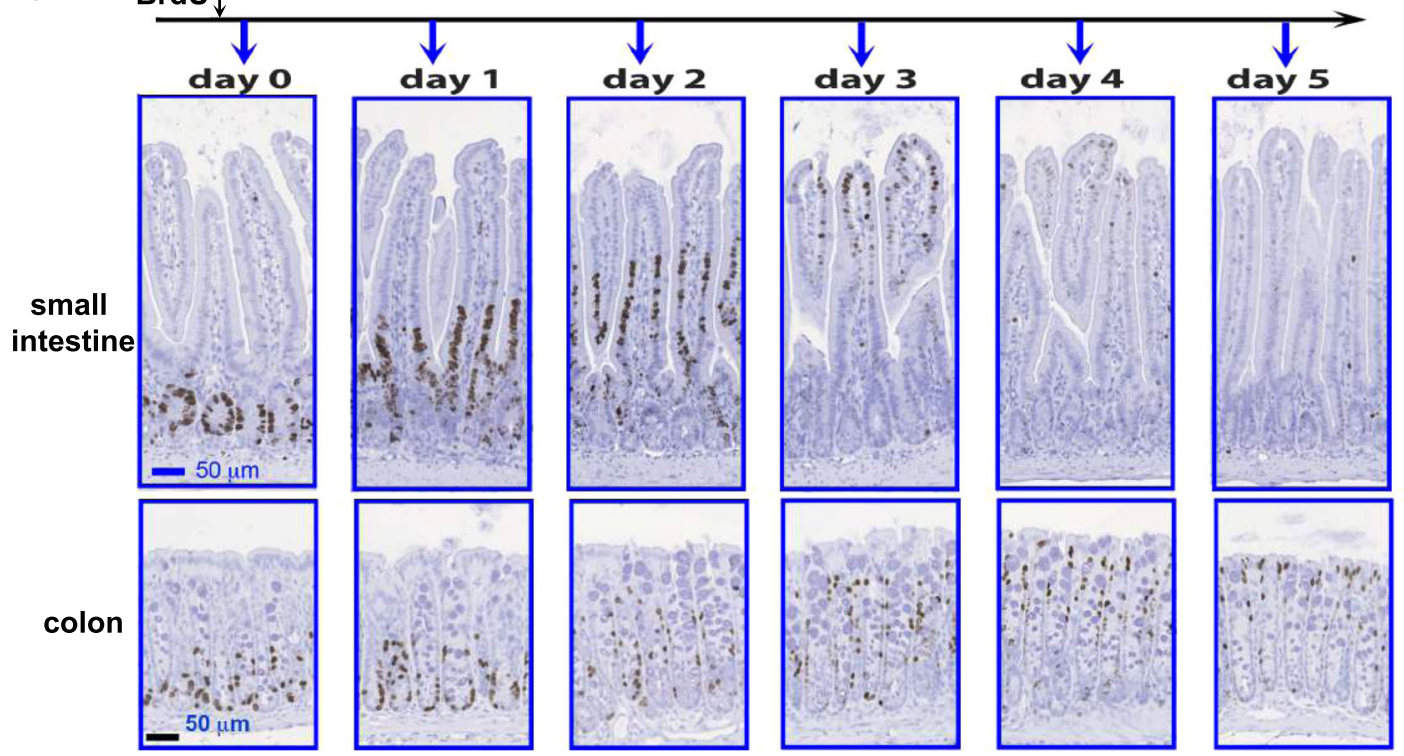

Fig. 8 Rpap3 activity in intestinal crypts correlates with tissue turnover. a Schematic representation of the experimental setting. Eight-week-old Lgr5GFP-IRES-CreER ${ }^{T 2}$; Rpap3flox/flox mice received five sequential intra-peritoneal injections of tamoxifen and were analyzed 7 or 10 days after the first injection. In this genetic model, the Cre is expressed in the Lgr5+ CBC stem cells labeled by GFP (see scheme on the right). b Representative images of tissue sections labeled by immunofluorescence with antibodies against GFP (green) and Rpb1 (red), with DAPI counter-staining of nuclei (blue). Please note the mosaic expression of GFP. Panels are representative for 5 animals/time point from two independent experiments. White arrow: GFP+ crypts. Asterisks: GFP- crypts. Scale bars (40 or $20 \mu \mathrm{m}$ ) are identical for matching panels. c Images are intestine tissue sections of wild-type animals stained for BrdU. Animals received one BrdU injection and were sacrificed at the indicated time point. The experiment was repeated twice ( 2 to 4 animals/time point from two different experiments). Scale bars $(50 \mu \mathrm{m})$ are identical for all pictures. 
a R2TP mRNA levels in CR tumor tissues

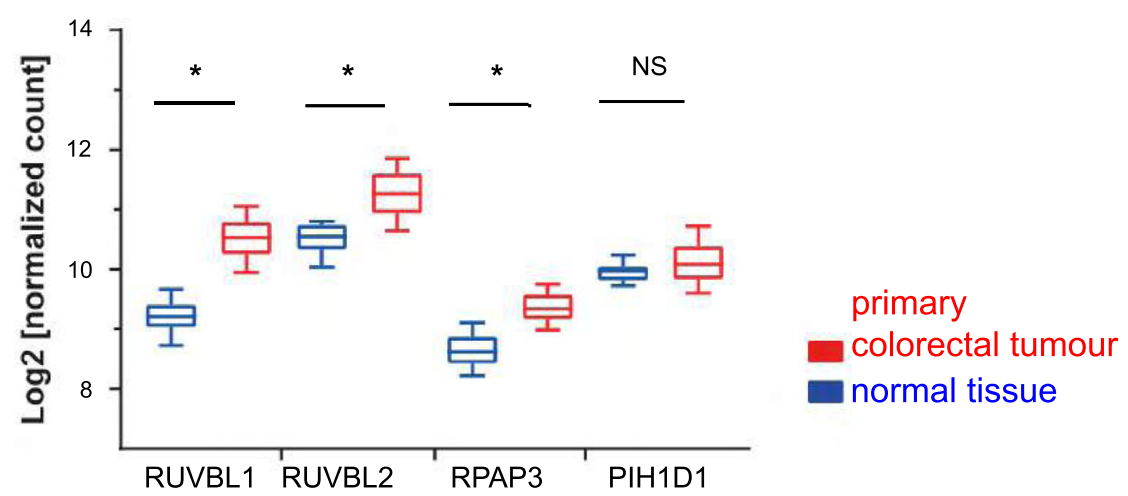

\section{b Disease-free survival of CRC patients according to RPAP3 in CR tumor tissues}
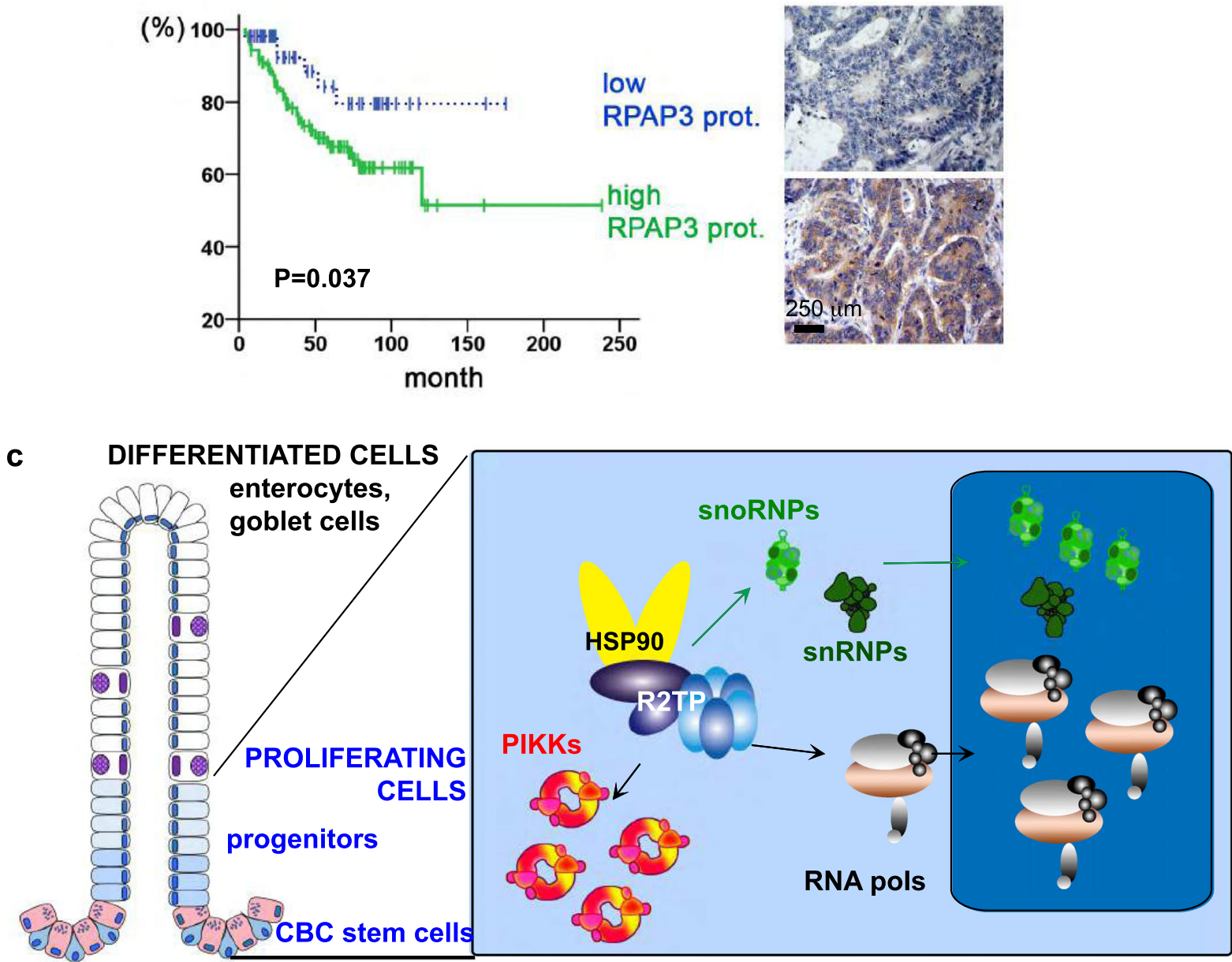

$$
\begin{aligned}
& \text { active } \\
& \text { R2TP }
\end{aligned}
$$

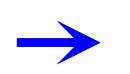
assembly of cellular machineries

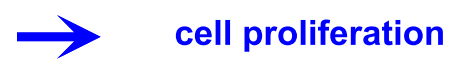

inactive
R2TP cytoplasmic Rpb1,

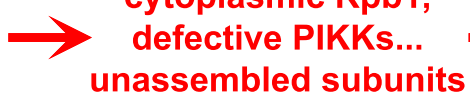

\p53

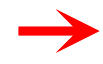

cell cycle arrest
\& apoptosis public and private cancer genomics data visualization and interpretation https:// xenabrowser.net $/{ }^{75}$. One-way ANOVA test was performed using GraphPad Prism 5.0.

For the outcome endpoints of human data, the DFS was defined as the measure of time after treatment during which one of the following events occurred: relapse at local or distant sites, or intercurrent death without recurrence. OS was defined as the time between surgery and death from any cause. Survival curves were analyzed by the Kaplan-Meier method and compared using the log-rank test. Cox's proportional hazards model, adjusted for other prognostic factors (i.e., gender, tumor location, tumor grade, tumor stage, and RPAP3 status), was used to evaluate the association of RPAP3 expression with outcome. Spearman correlation was used to analyze the 
Fig. 9 R2TP expression correlates with pathological cell proliferation. a The graph depicts transcript levels of R2TP components in human primary colorectal tumor samples $(n=380)$, as compared to normal solid tissues $(n=51)$ from COADREAD cohort. $y$-axis: Log2 normalized counts for the indicated transcript. Distributions are presented as box-and-whisker plots (center line: median; box limits, first and third quartiles; whiskers, 10th and 90 th percentiles). Statistical significance was determined by one-way ANOVA ( $\left.{ }^{*} p<0.001\right)$. b Kaplan-Meier analysis of disease-free survival among 177 CRC patients according to the proportion of RPAP3-expressing cells in tumor tissues. Solid green line and dashed blue line indicate high and low proportion of RPAP3-expressing tumoral cells, respectively. Statistical significance was determined by log-rank test $(P=0.037)$. Right panels show examples of CRC tissues with low (top) or high (bottom) RPAP3 expression, with scale bar. c Proposed model for R2TP activity in the small and large intestine. R2TP assembles cellular machineries such as RNA polymerases, snoRNPs, snRNPs, and PIKKs-complexes in CBCs and progenitors in the proliferative compartment (blue cells). Differentiated cells (including Paneth cells from the small intestine crypts, in pink) mostly rely on the complexes assembled during the proliferative phase. A defect in R2TP activity induces client dysfunction, cell cycle arrest and apoptosis via p53, and eventually, epithelium degradation.

correlation between the expression of RPAP3 and mTOR. Statistical analysis were performed with the SPSS 15.0 (SPSS Inc., Chicago, IL).

All other statistical analysis were performed employing GraphPad Prism 5.0.

\section{Sample availability}

Mouse sperm for the different strains is available upon request, as well as proprietary antibodies.

Reporting summary. Further information on research design is available in the Nature Research Reporting Summary linked to this article.

\section{Data availability}

The datasets analyzed during the current study for the transcriptomic analysis of R2TP subunits in human samples (Fig. 9a) used the UCSC Xena platform for public and private cancer genomics data visualization and interpretation available at https://xenabrowser. net $/{ }^{75}$. The datasets concerning the patient biopsies (Fig. 9b, Supplementary Fig. 7) are not publicly available because the database contains sensitive information that could compromise patient privacy but are available. Access to the original clinical records are subject to restrictions due to legal and privacy reasons. It must be authorized by the single patient or patient's legally authorized representative, and a specific request must be issued to: Direzione Medica/Presidio Ospedaliero "SS. Annunziata"; ASL02 di LancianoVasto-Chieti/Via Dei Vestini/66100 Chieti (Italy). Timeframe for response is usually 1 month. The remaining datasets that support the findings of this study are available in the Article, Supplementary Information, or, together with details about the experimental procedures, are available from the corresponding author upon reasonable request. Source data are provided with this paper.

Received: 10 January 2020; Accepted: 5 July 2021;

Published online: 10 August 2021

\section{References}

1. Zhao, R. et al. Navigating the Chaperone Network: an integrative map of physical and genetic interactions mediated by the Hsp90 Chaperone. Cell 120, 715-727 (2005).

2. Schopf, F. H., Biebl, M. M. \& Buchner, J. The HSP90 chaperone machinery. Nat. Rev. Mol. Cell Biol. 18, 345-360 (2017).

3. Coulombe, B., Bertrand, E. \& Houry, W. A. PAQosome: An R2TP-based chaperone for quaternary structure formation. Trends Biochem. Sci. 43, 4-9 (2018).

4. Hořejší, Z. et al. Phosphorylation-dependent PIH1D1 interactions define substrate specificity of the R2TP cochaperone complex. Cell Rep. 7, 19-26 (2014).

5. Abel, Y. et al. Structure of the RPAP3:TRBP interaction reveals an involvement of the HSP90/R2TP chaperone complex in dsRNA pathways. bioRxiv https://doi.org/10.1101/2020.11.11.367672 (2020).

6. Pal, M. et al. Structural basis for phosphorylation-dependent recruitment of Tel2 to Hsp90 by Pih1. Structure 22, 805-818 (2014).

7. Henri, J. et al. Deep structural analysis of RPAP3 and PIH1D1, two components of the HSP90 Co-chaperone R2TP complex. Structure 26, 11961209 (2018).

8. Zhou, C. Y. et al. Regulation of Rvb1/Rvb2 by a domain within the INO80 Chromatin remodeling complex implicates the yeast Rvbs as protein assembly Chaperones. Cell Rep. 19, 2033-2044 (2017).

9. Zaarur, N. et al. RuvbL1 and RuvbL2 enhance aggresome formation and disaggregate amyloid fibrils. EMBO J. 34, 2363-2382 (2015).

10. Martino, F. et al. RPAP3 provides a flexible scaffold for coupling HSP90 to the human R2TP co-chaperone complex. Nat. Commun. 9, 1501 (2018).
11. Maurizy, C. et al. The RPAP3-Cterminal domain identifies R2TPlikequaternary chaperones. Nat. Commun. 9, 2093 (2018)

12. Muñoz-Hernández, H. et al. Structural mechanism for regulation of the AAAATPases RUVBL1-RUVBL2 in the R2TP co-chaperone revealed by cryo-EM Sci. Adv. 5, eaaw1616 (2019).

13. Jha, S. \& Dutta, A. RVB1/RVB2: running rings around molecular biology. Mol. Cell 34, 521-533 (2009).

14. Zhao, R. et al. Molecular chaperone Hsp90 stabilizes Pih1/Nop17 to maintain R2TP complex activity that regulates snoRNA accumulation. J. Cell Biol. 180, 563-578 (2008).

15. Boulon, S. et al. The Hsp90 chaperone controls the biogenesis of L7Ae RNPs through conserved machinery. J. Cell Biol. 180, 579-595 (2008).

16. Bizarro, J. et al. NUFIP and the HSP90/R2TP chaperone bind the SMN complex and facilitate assembly of U4-specific proteins. Nucleic Acids Res. 43 8973-8989 (2015)

17. Malinová, A. et al. Assembly of the U5 snRNP component PRPF8 is controlled by the HSP90/R2TP chaperones. J. Cell Biol. 216, 1579-1596 (2017).

18. Cloutier, P. et al. R2TP/Prefoldin-like component RUVBL1/RUVBL2directly interacts with ZNHIT2 to regulateassembly of U5 small nuclear ribonucleoprotein. Nat. Commun. 8, 1-14 (2017).

19. Boulon, S. et al. HSP90 and its R2TP/Prefoldin-like cochaperone are involved in the cytoplasmic assembly of RNA polymerase II. Mol. Cell 39, 912-924 (2010).

20. Cloutier, P. \& Coulombe, B. New insights into the biogenesis of nuclear RNA polymerases? Biochem. Cell Biol. 88, 211-221 (2010).

21. von Morgen, P. et al. MRE11 stability is regulated by CK2-dependent interaction with R2TP complex. Oncogene 36, 4943-4950 (2017).

22. Hořejší, Z. et al. CK2 phospho-dependent binding of R2TP complex to TEL 2 is essential for MTOR and SMG1 stability. Mol. Cell 39, 839-850 (2010).

23. Boulon, S., Bertrand, E. \& Pradet-Balade, B. HSP90 and the R2TP cochaperone complex: building multi-protein machineries essential for cell growth and gene expression. RNA Biol. 9, 148-154 (2012).

24. Goto, G. H. et al. Two separate pathways regulate protein stability of ATM/ ATR-related protein kinases Mec1 and Tel1 in budding yeast. PLoS Genet. 13, e1006873 (2017).

25. Kakihara, Y., Makhnevych, T., Zhao, L., Tang, W. \& Houry, W. A. Nutritional status modulates box C/D snoRNP biogenesis by regulated subcellular relocalization of the R2TP complex. Genome Biol. 15, 404 (2014).

26. Benbahouche, N. E. H. et al. Drosophila Spag is the homolog of RNA polymerase II-associated protein 3 (RPAP3) and recruits the heat shock proteins 70 and 90 (Hsp70 and Hsp90) during the assembly of cellular machineries. J. Biol. Chem. 289, 6236-6247 (2014).

27. Chen, D. et al. Spaghetti, a homolog of human RPAP3 (RNA polymerase IIassociated protein 3), determines the fate of germline stem cells in Drosophilaovary. Cell Biol. Int. 42, 769-780 (2017).

28. Grad, I. et al. The molecular Chaperone Hsp90a is required for meiotic progression of spermatocytes beyond pachytene in the mouse. PloS ONE $\mathbf{5}$, e15770 (2010)

29. Voss, A. K., Thomas, T. \& Gruss, P. Mice lacking HSP90beta fail to develop a placental labyrinth. Development 127, 1-11 (2000).

30. Vermeulen, L. \& Snippert, H. J. Stem cell dynamics in homeostasis and cancer of the intestine. Nat. Rev. Cancer 14, 468-480 (2014).

31. Barker, N. Adult intestinal stem cells: critical drivers of epithelial homeostasis and regeneration. Nat. Rev. Mol. Cell Biol. 15, 19-33 (2013).

32. Izumi, N., Yamashita, A., Hirano, H. \& Ohno, S. Heat shock protein 90 regulates phosphatidylinositol 3-kinase-related protein kinase family proteins together with the RUVBL1/2 and Tel2-containing co-factor complex. Cancer Sci. 103, 50-57 (2012).

33. Kranz, A. et al. An improved Flp deleter mouse in C57Bl/6 based on Flpo recombinase. Genesis 48, 512-520 (2010). 
34. El Marjou, F. et al. Tissue-specific and inducible Cre-mediated recombination in the gut epithelium. Genesis 39, 186-193 (2004).

35. van Es, J. H. et al. A critical role for the Wnt effector Tcf4 in adult intestinal homeostatic self-renewal. Mol. Cell. Biol. 32, 1918-1927 (2012).

36. Koch, S. Extrinsic control of Wnt signaling in the intestine. Differ. Res. Biol. Divers 97, 1-8 (2017).

37. van der Flier, L. G., Haegebarth, A., Stange, D. E., van de Wetering, M. \& Clevers, H. OLFM4 is a robust marker for stem cells in human intestine and marks a subset of colorectal cancer cells. Gastroenterology 137, 15-17 (2009).

38. Hoter, A., El-Sabban, M. E. \& Naim, H. Y. The HSP90 family: structure, regulation, function, and implications in health and disease. Int. J. Mol. Sci. 19, 2560 (2018).

39. Abel, Y. et al. NOPCHAP1 is a PAQosome cofactor that helps loading NOP58 on RUVBL1/2 during box C/D snoRNP biogenesis. Nucleic Acids Res. 49, 1094-1113 (2021).

40. Lemm, I. et al. Ongoing $\mathrm{U}$ snRNP biogenesis is required for the integrity of Cajal bodies. Mol. Biol. Cell 17, 3221-3231 (2006).

41. Takai, H., Wang, R. C., Takai, K. K., Yang, H. \& de Lange, T. Tel2 regulates the stability of PI3K-related protein kinases. Cell 131, 1248-1259 (2007).

42. Hurov, K. E., Cotta-Ramusino, C. \& Elledge, S. J. A genetic screen identifies the Triple T complex required for DNA damage signaling and ATM and ATR stability. Genes Dev. 24, 1939-1950 (2010).

43. Kaizuka, T. et al. Tti1 and Tel2 are critical factors in mammalian target of rapamycin complex assembly. J. Biol. Chem. 285, 20109-20116 (2010).

44. Chanrion, M. et al. Concomitant Notch activation and p53 deletion trigger epithelial-to-mesenchymal transition and metastasis in mouse gut. Nat. Commun. 5, 5005 (2014)

45. Schwitalla, S. et al. Loss of p53 in enterocytes generates an inflammatory microenvironment enabling invasion and lymph node metastasis of carcinogen-induced colorectal tumors. Cancer Cell 23, 93-106 (2013).

46. Afify, A., Durbin-Johnson, B., Virdi, A. \& Jess, H. The expression of CD44v6 in colon: from normal to malignant. Ann. Diagn. Pathol. 20, 19-23 (2016).

47. Guo, Y. et al. Cyclin A2 maintains colon homeostasis and is a prognostic factor in colorectal cancer. J. Clin. Investig. 131, e131517 (2021).

48. Barker, N. et al. Identification of stem cells in small intestine and colon by marker gene Lgr5. Nature 449, 1003-1007 (2007).

49. Tetteh, P. W. et al. Replacement of lost Lgr5-positive stem cells through plasticity of their enterocyte-lineage daughters. Stem Cell 18, 203-213 (2016).

50. Kim, S. G. et al. Metabolic stress controls mTORC1 lysosomal localization and dimerization by regulating the TTT-RUVBL1/2 complex. Mol. Cell 49, 172-185 (2013).

51. Machado-Pinilla, R., Liger, D., Leulliot, N. \& Meier, U. T. Mechanism of the $\mathrm{AAA}+\mathrm{ATPases}$ pontin and reptin in the biogenesis of H/ACA RNPs. RNA 18, 1833-1845 (2012).

52. Brandt, M. et al. mTORC1 inactivation promotes colitis-induced colorectal cancer but protects from APC loss-dependent tumorigenesis. Cell Metab. 27, 118-135.e8 (2018).

53. Takai, H., Xie, Y., de Lange, T. \& Pavletich, N. P. Tel2 structure and function in the Hsp90-dependent maturation of mTOR and ATR complexes. Genes Dev. 24, 2019-2030 (2010).

54. Gurley, K. E. \& Kemp, C. J. Ataxia-telangiectasia mutated is not required for p53 induction and apoptosis in irradiated epithelial tissues. Mol. Cancer Res. MCR 5, 1312-1318 (2007).

55. Gurley, K. E., Moser, R., Gu, Y., Hasty, P. \& Kemp, C. J. DNA-PK suppresses a p53-independent apoptotic response to DNA damage. EMBO Rep. 10, 87-93 (2009).

56. Stedman, A. et al. Ribosome biogenesis dysfunction leads to p53-mediated apoptosis and goblet cell differentiation of mouse intestinal stem/progenitor cells. Cell Death Differ. 22, 1865-1876 (2015).

57. Ljungman, M. Dial 9-1-1 for p53: mechanisms of $\mathrm{p} 53$ activation by cellular stress. Neoplasia 2, 208-225 (2000).

58. Zhang, F. et al. Ribosomal stress couples the unfolded protein response to p53dependent cell cycle arrest. J. Biol. Chem. 281, 30036-30045 (2006)

59. Pinard, M., Cloutier, P., Poitras, C., Gauthier, M.-S. \& Coulombe, B. The unphosphorylated form of the PAQosome core subunit RPAP3 binds ribosomal preassembly complexes to modulate ribosome biogenesis. bioRxiv https://doi.org/10.1101/2021.03.17.435124 (2021).

60. Ruzankina, Y. et al. Tissue regenerative delays and synthetic lethality in adult mice after combined deletion of Atr and Trp53. Nat. Genet. 41, 1144-1149 (2009).

61. Krastev, D. B. et al. A systematic RNAi synthetic interaction screen reveals a link between p53 and snoRNP assembly. Nat. Cell Biol. 13, 809-818 (2011).

62. Barthel, E. R. On the utility of a compartmental population kinetics model of intestinal epithelial stem cell proliferation and differentiation. Theor. Biol. Med. Model. 14, 25 (2017).

63. Boisvert, F.-M. et al. A quantitative spatial proteomics analysis of proteome turnover in human cells. Mol. Cell. Proteom. MCP 11, M111.011429 (2012).
64. Moor, A. E. et al. Spatial reconstruction of single enterocytes uncovers broad zonation along the intestinal villus axis. Cell 175, 1156-1167.e15 (2018).

65. Fierro-Monti, I. et al. Dynamic impacts of the inhibition of the molecular Chaperone Hsp90 on the T-cell proteome have implications for anti-cancer therapy. PloS ONE 8, e80425 (2013).

66. Echeverría, P. C., Bhattacharya, K., Joshi, A., Wang, T. \& Picard, D. The sensitivity to Hsp90 inhibitors of both normal and oncogenically transformed cells is determined by the equilibrium between cellular quiescence and activity. PloS ONE 14, e0208287 (2019).

67. Pillarsetty, N. et al. Paradigms for precision medicine in epichaperome cancer therapy. Cancer Cell 36, 559-573.e7 (2019).

68. Rodina, A. et al. The epichaperome is an integrated chaperome network that facilitates tumour survival. Nature 538, 397-401 (2016).

69. Vartholomaiou, E. et al. Cytosolic Hsp90alpha and its mitochondrial isoform Trap1 are differentially required in a breast cancer model. Oncotarget $\mathbf{8}$, 17428-17442 (2017)

70. Vartholomaiou, E., Echeverra, P. C. \& Picard, D. Unusual Suspects in the Twilight Zone Between the Hsp90 Interactome and Carcinogenesis. vol. 129 (Elsevier Inc., 2016)

71. Chatterjee, S. \& Burns, T. Targeting heat shock proteins in cancer: a promising therapeutic approach. Int. J. Mol. Sci. 18, 1978 (2017).

72. Neckers, L. \& Workman, P. Hsp90 molecular chaperone inhibitors: are we there yet? Clin. Cancer Res. J. Am. Assoc. Cancer Res. 18, 64-76 (2012).

73. Lattanzio, R. et al. Overexpression of activated phospholipase $\mathrm{C} \gamma 1$ is a risk factor for distant metastases in T1-T2, N0 breast cancer patients undergoing adjuvant chemotherapy. Int. J. Cancer 132, 1022-1031 (2012).

74. Brown, T. Southern blotting. Curr. Protoc. Immunol. Chapter 10, Unit 10.6A (2001).

75. Goldman, M. et al. The UCSC Xena platform for public and private cancer genomics data visualization and interpretation. biorxiv https://doi.org/ $10.1101 / 326470$ (2018).

\section{Acknowledgements}

We thank Solange Morera and EMBL facility for help with the anti-RPAP3 antibody, Laszlo Tora for the gift of anti-TRRAP. The ES cells were generated by the trans-NIH KnockOut Mouse Project (KOMP) and obtained from the KOMP Repository (www.komp.org). NIH grants to Velocigene at Regeneron Inc (U01HG004085) and the CSD Consortium (U01HG004080) funded the generation of gene-targeted ES cells for 8500 genes in the KOMP Program and archived and distributed by the KOMP Repository at UC Davis and CHORI (U42RR024244). We thank the CIGM team in Institut Pasteur for microinjection experiments and animal husbandry and Laurent Le Cam for help with $\operatorname{Trp} 53^{\text {flox }}$ model. We thank the RAM, PCEA, and ZEFI animal facilities, the MRI imaging facility, and the RHEM histology facility. MRI is member of the national infrastructure France-BioImaging supported by the French National Research Agency (ANR-10-INBS-04, "Investments for the future»). RHEM is supported by SIRIC Montpellier Cancer and funded by grant INCa_Inserm_DGOS_12553, the European Regional Development foundation and the Occitanie Region. The work was supported by La Ligue Nationale Contre le Cancer (équipes labelisées to E.B., P.J.), le comité Languedoc-Roussillon de la Ligue (LS 139433-2016 to B.P. B.), and the INCa grants PLBIO 2016-161 to D.H., E.B., M.H., B.P.B., and PLBIO 2018-158 to P.J. C.M. and C.A. had fellowships from la Ligue Nationale Contre le Cancer.

\section{Author contributions}

C.M., C.A., B.L., M.G., C.L., V.P., M.F., C.P., J.B., F.G., C. V., and B.P.B. performed experiments, F.L. generated murine model, N.T. and R.L. provided human TMA and analysis, D.H. analysed the CODREAD data, F.G., P.J., and D.H. advised on the work and commented critically on the paper. C.M., E.B., M.H., and B.P.B. conceived the study, designed the experiments, analysed the data, and wrote the paper. B.P.B. supervised the research. All authors approved the content of the paper.

\section{Competing interests}

The authors declare no competing interest.

\section{Additional information}

Supplementary information The online version contains supplementary material available at https://doi.org/10.1038/s41467-021-24792-4.

Correspondence and requests for materials should be addressed to E.B., M.H. or B.P-B

Peer review information Nature Communications thanks the anonymous reviewer(s) for their contribution to the peer review of this work. Peer reviewer reports are available.

Reprints and permission information is available at http://www.nature.com/reprints

Publisher's note Springer Nature remains neutral with regard to jurisdictional claims in published maps and institutional affiliations. 
(c) (i) Open Access This article is licensed under a Creative Commons Attribution 4.0 International License, which permits use, sharing, adaptation, distribution and reproduction in any medium or format, as long as you give appropriate credit to the original author(s) and the source, provide a link to the Creative Commons license, and indicate if changes were made. The images or other third party material in this article are included in the article's Creative Commons license, unless indicated otherwise in a credit line to the material. If material is not included in the article's Creative Commons license and your intended use is not permitted by statutory regulation or exceeds the permitted use, you will need to obtain permission directly from the copyright holder. To view a copy of this license, visit http://creativecommons.org/ licenses/by/4.0/.

(c) The Author(s) 2021, corrected publication 2022 